
\title{
25 Research Square \\ Mast Cell Sensitization as a Plausible and Researchable Mechanism for Chemical Intolerance
}

\section{Claudia S. Miller}

University of Texas UTHSCSA: The University of Texas Health Science Center at San Antonio

Raymond F Palmer ( $\triangle$ palmerr@uthscsa.edu )

University of Texas UTHSCSA: The University of Texas Health Science Center at San Antonio https://orcid.org/0000-0001-6621-9038

\section{Tania T. Dempsey}

AlM Center for Personalized Medicine

Nicholas A. Ashford

Massachusetts Institute of Technology

Lawrence B. Afrin

AIM Center for Personalized Medicine

\section{Discussion}

Keywords: Chemical Intolerance, Drug Intolerance, Environmental Exposure, Food Intolerance, Mast Cell, Regulatory Toxicology, Toxicant-induced Loss of Tolerance

Posted Date: May 27th, 2021

DOl: https://doi.org/10.21203/rs.3.rs-547748/v1

License: (c) (1) This work is licensed under a Creative Commons Attribution 4.0 International License.

Read Full License 


\section{Abstract \\ Background}

Worldwide observations provide evidence for a two-stage disease process called Toxicant-Induced Loss of Tolerance (TILT), described in this journal in the first of two related papers. The disease process is initiated by a major exposure event, or a series of lower level exposures (Stage I, Initiation). Subsequently, affected individuals report that common chemical inhalants, foods, and drugs trigger multisystem symptoms (Stage II, Triggering). Given that foods and drugs also are comprised of chemicals, we refer to these intolerances simply as "chemical intolerance" $(\mathrm{Cl})$. In this second, companion paper we propose mast cell sensitization and mediator release as a plausible and researchable biological explanation for TILT.

\section{Methods}

Using the Quick Environmental Exposure and Sensitivity Inventory (QEESI), we compared patients diagnosed with mast cell activation syndrome (MCAS) $(n=147)$ to individuals who reported chemical intolerances following various exposures $(n=345)$, and to controls $(n=76)$. We compared QEESI scores using ANOVA across groups. Clinical scores for the MCAS patient group were used to predict $\mathrm{Cl}$ status using logistic regression.

\section{Results}

As the likelihood of patients' having $\mathrm{Cl}$ increased, their likelihood of having MCAS similarly increased, to a near-perfect correspondence at the high ends of the QEESI and clinical MCAS scores. Symptom patterns were near-identical for $\mathrm{Cl}$ and MCAS groups.

\section{Conclusion}

The close correspondence between QEESI scores for MCAS and TILT patients supports mast cell sensitization and mediator release as a plausible biological mechanism underlying both conditions, with implications for medicine, environmental health, and regulatory toxicology.

\section{Introduction}

Chemical, food, and drug intolerances are growing international concerns [1-5]. These intolerances may arise following exposures to building construction or remodeling, pesticides, Gulf War chemicals, combustion products, surgical implants, mold, and many other sources [6]. The exposures may be onetime, acute events; a series of exposures; or long-term, low-level exposures. They often involve particular synthetic chemicals such as an organophosphate pesticide, a combination of synthetic substances, 
and/or their combustion products. These xenobiotics enter the body via well-known routes: inhalation, ingestion, skin contact, and/or injection/implantation. What remains unclear is why a subset of individuals would subsequently develop persistent intolerances to chemicals, foods, and drugs which never bothered them before and do not bother most people. Over the past 70 years, strikingly similar reports have emerged from patients, doctors, and researchers in different nations supporting the existence of a novel, or at least previously unrecognized, disease process.

There is accumulating evidence for a two-stage causal model which links initiation by chemicals with subsequent chemical, food, food additive, or medicine/drug triggers, called Toxicant-induced Loss of Tolerance $[7,8]$. The origins of these intolerances have been variously attributed to classical toxicity, allergy, and psychological factors [9-11]. Up to now, a precise mechanism has remained elusive.

As with other major categories of exposure-induced illnesses, such as classical toxicity or allergy, those who become ill have been presumed to be more genetically or epigenetically susceptible and/or may have been more heavily or frequently exposed than early evidence indicated. The perplexing question is "What is different about people who develop these intolerances versus those who do not?" In this paper we propose a plausible, parsimonious answer to this question.

In the last decade, our understanding of the evolutionarily ancient mast cell (MC) and its ability to effect a vast range of inflammatory, allergic, and other responses throughout the body has expanded rapidly. Several factors have resulted in the underestimation of the MC's pivotal role in disease: 1) Since the discovery of IgE, allergy's central focus has been on the humoral, as opposed to the cellular, immune system; 2) MCs' typically tiny numbers and their sparse distribution in most tissues have contributed to their anonymity; and 3) MCs are minimally present in circulation, and even where they dominate in peripheral tissues, it has been hard to identify and isolate them.

These sentinel cells guard the perimeters of our skin and other organs, warding off invaders and protecting our internal milieu. The $\mathrm{MC}$ is one of the first responders to most bodily invasions and insults. They are highly evolved, critical components of the cellular immune system [12]. Largely lying in wait, these warriors spring into action in milliseconds, deploying sophisticated molecular weaponry. If they perceive a major threat, they can release a vast array of mediators all at once. We have long been aware of MCs' ability to precipitate anaphylaxis in response to bee stings, peanuts, and other allergens in previously sensitized individuals. At a bare minimum, the release of histamine by MCs into the surrounding tissues and bloodstream leads to immediately recognizable hives, hypotension, syncope, respiratory arrest, and even death. We now understand, however, that there is an extensive array of other mediators that MCs differentially release in response to varying stimuli. In addition, MCs are sensitizable, that is, they remember past invaders. Receptors decorate their exterior surfaces. These miniature detectors, alone or in varying combinations, can identify an extraordinary array of signals and are capable of precise responses. They are first to recognize when, where, and what sort of threat is looming. Over roughly a half-billion years, MCs have evolved their capacity to identify invaders and select precisely which weapons to deploy, in what order, and for how long [12]. Even while an MC is called to action 
(activated) to launch its pre-formed armaments, it can signal other cells to the join the battle. Meanwhile, behind the frontline, MCs are reloading their weapons and stockpiling new munitions. Thus, our so-called "primitive" immune system is in fact quite sophisticated. It was many decades following the discovery of $\lg \mathrm{E}$ and its relationships to anaphylaxis and classical allergies (such as to pollens, animal dander, and dust mites) that we learned of the MCs' capacity to respond to a bewilderingly broad range of stimulirevealing a new, alternative pathway for their activation and degranulation, even in the absence of "classic" binding of antigen with multiple molecules of MC-surface-bound IgE.

The fact that chemically intolerant individuals often report immediate symptoms following seemingly insignificant exposures, such as a whiff of fragrance, has led some to speculate that the mechanism must be neurological. Notably, mast cells may rapidly release, or gradually leak, mediators some of which are pre-formed. In fact, there is no cellular element of the immune system that can react faster than mast cells. Lymphocytes require hours to activate, and neutrophils require minutes, but mast cells can respond to a trigger in sub-second time [13-16].

The links between our contemporary exposures and our ancient mast cells appear to have been missed. Since WWII, more and more synthetic organic chemicals have crept into our personal environments. In response to the oil embargo and consequent energy conservation efforts in the 1970s, many U.S. homes and buildings were sealed more tightly, resulting in insufficient fresh air. This has resulted in the accumulation of every sort of indoor air contaminant to higher levels than ever before (e.g., volatile organic chemicals outgassing from new construction and remodeling materials, pesticides, mold, disinfectants, and cleaning agents) [6]. Only now, are we learning that our contemporary exposures may be provoking MCs to release their broad range of inflammatory mediators, resulting in a condition called "Mast Cell Activation Syndrome" (MCAS) [17]. Theoharides et al. [18] propose that the diagnosis "Mast Cell Mediator Disorders (MCMD)" be used whenever unique mast cell mediators are measurable.

We propose mast cell activation (MCA), with mediator release implicit in that process, as a plausible biological mechanism underlying chemical intolerance $(\mathrm{Cl})$. If $\mathrm{MCA}$ and $\mathrm{Cl}$ are closely related, they should share similar pathophysiologies and exhibit parallel symptoms and intolerances. In this paper, we explore these parallels.

\section{Background}

Converging lines of evidence support MCA as a plausible unifying explanation for a host of previously unexplained illnesses, including $\mathrm{Cl}$.

Mast Cell Activation Syndrome: Mast Cells (MCs) are components of the ancient cellular, or intrinsic, immune system which evolved over 500 million years ago, predating adaptive immunity and immunoglobulins [19]. For a variety of reasons, including the fact that MCs do not circulate in the blood in significant numbers, they have been difficult to study. MCs are present-generally in low numbers and sparsely distributed-typically at the interfaces between our tissues and the external environment, including the skin, and the respiratory, gastrointestinal, and genitourinary tracts, as well as in the walls of 
all vessels-precisely where one would expect a principal host defense effector cell to be sited. These tissue-dwelling cells originate in the bone marrow and then migrate via the bloodstream to reach their target tissues, where they continue to mature and reside for an average of 2-4 years, with little mobility or chemotaxis compared to other leukocytes [20].

Once MCs reach their destinations, they continue to differentiate in ways that are specific to the tissue and the intrinsic and extrinsic environment, including any chemicals, foods, and drugs encountered. Once triggered, MCs can release more than 1000 distinct mediators [21] resulting in inflammation, allergy-like symptoms, or altered tissue growth and development. A real-time video shows how quickly mast cells degranulate and release mediators (Video S1). Notably, too, these MC mediators can continue to provoke the very MCs that produced them, resulting in a vicious, self-stimulating feedback loop. For example, the presence of activating histamine $\mathrm{H} 1$ and $\mathrm{H} 2$ receptors on the surface of the $\mathrm{MC}$ provides at least part of the rationale for use of both $\mathrm{H} 1$ and $\mathrm{H} 2$ blockers in MCAS patients, most of whom gain distinct benefits from each of these therapeutic classes [22-25].

Fully differentiated MCs bear a wealth of specific cell-surface receptors (more than 250 [21]), e.g., the KIT transmembrane tyrosine kinase receptor which is the principal $\mathrm{MC}$ regulatory element, and the Fce RI receptor for IgE-class immunoglobulin [26, 27]. Although IgE antibodies can stimulate FcERI once they bind antigen [28], MCs respond to a wide variety of environmental cues that can trigger them to release pre-stored and/or newly synthesized mediators. The final stages of MC differentiation occur in the tissues in which they reside, with different types of MCs present in different tissues. MCs respond by releasing mediators particular to the insult and its anatomic location. Upon triggering, whether by docking of a triggering substance with a MC-surface receptor, or by action of a triggering force (e.g., temperature change, pressure change, specific wavelength exposure) on a force-sensing element of the MC, MCs can release mediators in a fraction of a second $[13,14]$. In contrast, neutrophils require minutes, and lymphocytes hours, to activate $[29,14]$. MCs' ability to respond precisely and rapidly to a vast range of environmental triggers suggests they may possess unique epigenetic and transcriptional capabilities that enable them to adapt rapidly to environmental challenges [30].

Although the proposed diagnostic criteria for MCAS [31-34, 17] differ in some specific respects, MCAS diagnosis typically rests upon: 1 ) chronic and/or recurrent symptoms consistent with aberrant MC mediator release; 2) the exclusion of other conditions that might better explain the patient's symptoms; and 3) laboratory evidence of MC activation. Generally accepted laboratory markers of MCAS include elevated levels (in blood or urine, as appropriate for each metabolite) of tryptase or a few other mediators relatively specific to the $M C$ (e.g., heparin, histamine and its principal immediate urinary metabolite $\mathrm{N}$ methylhistamine, prostaglandin D2 and its immediate metabolite 11-beta-prostaglandin-F2-alpha, chromogranin A, and leukotriene E4). Clinical experience to date has shown that most patients diagnosed by these criteria respond to MC-targeted treatments. One of the most specific laboratory tests for MC activation is serum tryptase, although this typically is elevated, and only mildly, in about $9-16 \%$ of MCAS patients $[34,35]$. Further, tryptase is somewhat thermolabile and is constitutively released and thus may not be found elevated in many patients with MC activation [35]. 
Drugs that inhibit MC degranulation (e.g., cromolyn, ketotifen) or block mediator effects (e.g., welltolerated combinations of histamine type $\mathrm{H} 1$ and $\mathrm{H} 2$ receptor antagonists administered simultaneously, typically twice daily) often help reduce symptoms. At present, it is not possible to predict which drugs are most likely to help which symptoms in which MCAS patients, thereby requiring both patient and physician to practice great patience, persistence, and a methodical approach for empirically testing the fortunately large array of treatments that have been already found helpful for some MCAS patients. Treatment is palliative, not curative [31-34, 36]. For example, topical diphenhydramine or cromolyn may be helpful for female MCAS patients suffering chronic dyspareunia, vaginitis, or dysfunctional uterine bleeding consequential to their MCA [37]. Although severe morbidity and early mortality may occur, limited data suggest most MCAS patients can expect a normal lifespan.

Chemical Intolerance: Characteristically, $\mathrm{Cl}$ individuals report multi-system symptoms and new-onset intolerances triggered by structurally unrelated chemicals, foods, and drugs-substances that these individuals say never bothered them previously and do not other most people. Many patients attribute onset of their illness and intolerances to a well-defined exposure event, such as the Gulf War, disasters like the World Trade Center, indoor air contaminants, or flood or water-damaged buildings resulting in mold and bacterial growth [38]. Different family members or co-workers who become ill frequently exhibit different manifestations, thus confounding physicians and public health investigators [6].

The steps, or process, leading to $\mathrm{Cl}$ differ from those preceeding infectious diseases or classical toxicity. Individuals affected by a particular infectious agent or toxicant generally share recognizable constellations of symptoms. This is not the case for $\mathrm{Cl}$ patients, which explains, in part, why this condition has defied numerous attempts to establish a consensus case definition. Indeed, it appears we may be dealing with a new mechanism and category of disease.

Accumulating worldwide reports by patients, physicians, and researchers point to a two-step process [3943]. Miller $[6,44,45]$ proposed Toxicant-Induced Loss of Tolerance (TILT). This term captures the wide variety of multi-system symptoms and intolerances associated with the condition. TILT develops in two stages: Initiation by a major exposure event, or a series of exposures (Stage I, Initiation), followed by triggering of multisystem symptoms in response to everyday chemical inhalants, foods/food additives, and/or medications/drugs (Stage II, Triggering), often at much lower exposure levels than those found in classical toxicity. Initiating exposures include chemical spills, pesticides, cleaning agents, solvents, combustion products, medications and medical devices, as well as indoor air contaminants associated with materials used in construction or remodeling [6, 44 - 46] (see Figures 1 and 2).

The reigning paradigms in allergy, immunology, and occupational/environmental medicine have not widely embraced MCAS or TILT, or agreed upon case definitions for them [47-49]. Although most doctors have some awareness of $\mathrm{Cl}$, few are aware of MCAS at all. It follows that the few doctors who evaluate TILT patients are not testing for MCAS. Based upon our prior work, it appears that MCAS and TILT may be part of the same "iceberg," both submerged below a waterline of clinical recognizability [7]. 
Prevalence of $\mathrm{Cl}$ and MCAS: By one estimate, $10-17 \%$ of the German population may have MCAS [50]. $\mathrm{Cl}$ prevalence estimates range from 8-33\% in population-based surveys [51-53]. Hojo et al. [2] in Japan and Steinemann [1] in the U.S. each conducted surveys of chemical intolerance in their respective countries on two separate occasions, a decade apart. According to their research, in just 10 years, substantial increases in $\mathrm{Cl}$ occurred in both countries.

The Quick Environmental Exposure and Sensitivity Inventory (QEESI), developed by the senior author of this paper, is considered the reference standard for assessing $\mathrm{Cl}$ and has become a surrogate case definition used by researchers in more than 15 countries in approximately 80 peer-reviewed studies $[1,39,41-43,54]$. This validated, self-administrable, 50-item questionnaire is used for: (1) Research-to characterize and compare study populations, and to select subjects and controls; (2) Clinical Evaluations -to obtain profiles of patients' self-reported symptoms and intolerances; the QEESI can be used at intervals to follow symptoms over time or to document responses to treatments or exposure avoidance; and (3) Workplace, Community, or Epidemiological Investigations -to identify those who may be more chemically susceptible and/or measure changes in symptoms and intolerances in exposed versus control groups.

The QEESI has four scales: Symptom Severity, Chemical Intolerances, Other Intolerances, and Life Impact. Each scale item is scored from 0 to $10(0=$ "not a problem" to $10=$ "severe or disabling problem"). There is also a 10-item Masking Index which gauges ongoing exposures (such as to caffeine or tobacco) that can reduce individuals' awareness of their intolerances [55].

Connecting MCAS and TILT: Our understanding of the possible role for MCs in TILT is recent. Both patients with MCAS and those with TILT commonly report symptoms in multiple organ systems and often several systems simultaneously. MCs produce and release scores of chemical signals (generically termed "mediators") that can affect organs, tissues, and systems throughout the body.

TILT encompasses exposures that may have initiated illness and exposures that continue to trigger symptoms. However, until now, TILT has lacked a clear biological mechanism, which MCAS may provide. An understanding of TILT initiation and triggering offers strategies for prevention and intervention, many of which appear applicable to MCAS. Knowledge of the MCAS mechanism has the potential to inform new medical interventions and treatments for TILT. Failure to eliminate or reduce initiators such as pesticides or mold can result in chronic, even lifelong, illness in susceptible people. This suggests persistent $\mathrm{MC}$ activation and degranulation. The symptoms and findings in TILT patients may be best understood in the context of MCs and the mediators they release.

Together, MCAS and TILT satisfy the principle of parsimony (i.e., Occam's Razor). Table 2 summarizes prominent features of each. TILT serves as an umbrella category for these exposure-driven illnesses, while MCAS offers an umbrella mechanism uniting illnesses driven by MC activation.

\section{Table 1. Representative Examples of Key Mast Cell Mediators}


Pro-inflammatory cytokines

IL-1a, IL-1 $\beta$, IL-2, IL-4, IL-5, IL-6, IL-7, IL-9, IL-10, IL-12, IL-13, IL-15, IL-16, IL-18, IL-21, IL-23, IL-25, IL-31, IL-33, IFN- - , TNF-a

Chemokines

MCP-1, IL-8, RANTES, eotaxin, leukotrienes $B_{4}, C_{4}, D_{4}, E_{4}$ (SRS-A), CCL2, CCL3, CCL4, CCL5, CCL11, CCL19, CCL20, CCL21, CXCL8, CXCL10, XCL-1

\section{Proteases}

Tryptase, chymase, angiotensin converting enzyme (ACE), ACE2, carboxypeptidase, cathepsin G, cysteinyl cathepsins, metalloproteinases

\section{Growth factors}

IL-3, GM-CSF, bFGF, VEGF, TGF- $\beta$, PDGF, EGF, NGF, SCF, angiopoietin

Vascular permeability, vasodilatation

Histamine, 5-hydroxytryptamine, tryptase, NO, VLA4

Platelet aggregation and thrombosis:

PAF, thromboxane

Neurohormones

Adrenocorticotrophin (ACTH), CRH, endorphins, HKA, leptin, melatonin, NT, SP, VIP

Heparin proteoglycan

Chondroitin sulfate proteoglycan

Superoxide dismutase

Acid hydrolases

Glucuronidase, galactosidase, hexosaminidase, peroxidase

Arylsulphatase A

Prostaglandin $D_{2}$, thromboxane

Serotonin, dopamine 
Antimicrobial agents

IFN- $\alpha$, IFN- $\beta$, IFN- - , human cathelicidin (LL-37)

TSLP

Table 2. Features of TILT and MCAS Compared 


\begin{tabular}{|c|c|c|}
\hline & TILT & MCAS \\
\hline Multisystem symptoms & $\begin{array}{l}\sqrt{ } \text { Driven by high level or repeated } \\
\text { low level exposures }\end{array}$ & $\begin{array}{l}\sqrt{ } \text { Lifelong } \\
\text { susceptibility } \\
\text { exacerbated by } \\
\text { exposure }\end{array}$ \\
\hline Age at diagnosis & $\sqrt{ }$ Exposure driven, wide range & $\begin{array}{l}\sqrt{ } \text { Wide range } \\
\text { (mean } 49 y / 0,16-92)\end{array}$ \\
\hline Age symptom onset & $\sqrt{ }$ Wide range & $\sqrt{ }$ Wide range \\
\hline Brain fog & $\sqrt{ }$ & $\sqrt{ }$ \\
\hline Diverse initiators and triggers & $\sqrt{ }$ Emphasis on synthetic chemicals & $\sqrt{ }$ \\
\hline Female predominance & $\sqrt{ }$ & $\sqrt{ }$ \\
\hline Parallels to addiction & $\begin{array}{l}\text { Emphasized; chemical, food, and } \\
\text { drug addictions common }\end{array}$ & $\begin{array}{l}\text { Possible, but } \\
\text { unknown }\end{array}$ \\
\hline Withdrawal symptoms & $\begin{array}{l}\text { Reported for many chemicals, foods, } \\
\text { and drugs }\end{array}$ & Unknown \\
\hline $\begin{array}{l}\text { Avoidance of major triggers } \\
\text { (abdiction) }\end{array}$ & $\sqrt{ }$ & $\sqrt{ }$ \\
\hline Biomarkers/lab tests & None diagnostic & $\begin{array}{l}\text { Few }(\mathrm{PgD} 2, \text { heparin, } \\
\text { histamine); } \\
\text { unstable; special } \\
\text { handling required }\end{array}$ \\
\hline Brain imaging & $\begin{array}{l}\text { Several studies; mixed results and } \\
\text { interpretations }\end{array}$ & $\begin{array}{l}\text { Possible, but } \\
\text { unknown }\end{array}$ \\
\hline $\begin{array}{l}\text { Symptoms and severity vary greatly } \\
\text { over time in an affected individual }\end{array}$ & $\sqrt{ }$ & $\sqrt{ }$ \\
\hline $\begin{array}{l}\text { Induction (that is, sensitization) by a } \\
\text { wide range of environmental agents }\end{array}$ & $\sqrt{ }$ & $\sqrt{ }$ \\
\hline $\begin{array}{l}\text { Subsequent triggering by lower levels } \\
\text { of exposure than those involved in } \\
\text { initial induction of the illness }\end{array}$ & $\sqrt{ }$ & $\begin{array}{l}\text { Possible, but } \\
\text { unknown }\end{array}$ \\
\hline $\begin{array}{l}\text { Concomitant chemical, food, and } \\
\text { drug intolerances }\end{array}$ & $\begin{array}{l}\sqrt{ } \text { Multiple intolerances to } \\
\text { chemicals, foods, and drugs }\end{array}$ & $\begin{array}{l}\sqrt{ } \text { More emphasis } \\
\text { on drugs }\end{array}$ \\
\hline $\begin{array}{l}\text { "Spreading" of sensitivity to other, } \\
\text { often chemically dissimilar } \\
\text { substances; each substance may } \\
\text { trigger a different constellation of } \\
\text { symptoms }\end{array}$ & $\sqrt{ }$ & $\begin{array}{l}\text { Possible, but } \\
\text { unknown }\end{array}$ \\
\hline $\begin{array}{l}\text { Adaptation (masking), that is, } \\
\text { acclimatization to environmental } \\
\text { incitants, both chemical and food, } \\
\text { with continued exposure; loss of this }\end{array}$ & $\sqrt{ }$ & $\begin{array}{l}\text { Possible, but } \\
\text { unknown }\end{array}$ \\
\hline
\end{tabular}


tolerance with removal of the

incitant(s); and augmented response

with reexposure after an appropriate

interval (for example, 4 to 7 days)

Medical evaluation and treatment

Detailed exposure history to identify chemical, food, and drug initiators and triggers. Avoidance of problem exposures and synthetic products. Organic foods, clean air (HEPA and charcoal filters), clean water (filters), natural medicines/supplements, and consumer products.

Rotary/elimination diet
Avoidance of anything provoking symptoms including "stress." Use of drugs to stabilize mast cells and prevent mediator release and/or block mediator effects.

An apparent threshold effect sometimes referred to as the $\sqrt{ }$

Possible, but unknown patient's "total load"

MCAS, TILT, and the Nervous System: Our proposal that MCA could be the biological mechanism for TILT arises out of recent recognition that the realm of $\mathrm{MC}$ disease extends beyond clinically recognized allergic phenomena (e.g., allergy, anaphylaxis, urticaria, angioedema, atopic dermatitis or eczema) and is apart from the rare MC malignancy, mastocytosis. Mastocytosis, first described in cutaneous form in the latter part of the $19^{\text {th }}$ century and then in systemic form in the mid- $20^{\text {th }}$ century, manifests as chronic MC activation together with grossly excessive (indeed, frankly neoplastic) proliferation of MCs. Only recently (1980s) have researchers hypothesized the existence of MCAS [56,57]. In 2007, the first MCAS reports appeared, describing patients with heightened release of $M C$ mediators, yet without the excess numbers of MCs that characterize mastocytosis. Many of these mediators have potent but short-lived effects. They are released locally in sensitized tissues and are exquisitely thermolabile, posing major challenges for clinical measurement. This menagerie of MC mediators produces multisystem inflammation at minimum, and not uncommonly allergic-type phenomena, and sometimes aberrancies in growth and development (typically benign) in virtually any tissue.

As immunologic "first responders" in the central nervous system, activated MCs can initiate, amplify, and prolong wide-ranging neuroimmune responses [58]. Several investigators have pointed to neurogenic inflammation as a mechanism for $\mathrm{Cl}$ [59-61]. We suggest that rather than being the mechanism for $\mathrm{Cl}$, neuro-inflammation may be the result of mast cell activation and mediator release initiated by xenobiotic/chemical exposures. MCs can affect neuronal function from afar via their released mediators which bind with specific neuronal receptors [62]. Also, MCs physically abut neurons in many tissues, and wherever such dyads are present, there is constant mediator "cross-talk" between the two cells. Thus, MC activation can provoke nearby neurons, inducing their associated symptoms; similarly, neurons can provoke nearby MCs, inducing their associated symptoms.

Correspondingly, quieting of MCs can help reduce neuronal activation, and, again, vice versa. For a comprehensive review of mast cells, mediators, and their effects on the central nervous system, see Song et al. [63]. Table 1 lists mast cell mediators involved in neuroinflammation (after Theoharides et al. [20]; 
also, [64-66]). This is not an exhaustive list. Many investigators have documented neuroinflammation and inflammatory mediators in chemical intolerance [61, 67-69].

With permission from Theoharides TC et al., Immunol Rev 2007, Theoharides TC, Exp Dermatol 2017, Theoharides TC, Biofactors 2020. Abbreviations: bFGF: basic fibroblast growth factor; CCL: chemokine (C-C motif) ligand; $\mathrm{CRH}$ : corticotropin releasing hormone; $\mathrm{CXCL}$ : chemokine (C-X-C motif) ligand; EGF: epidermal growth factor; GM-CSF: granulocyte-macrophage colony stimulating factor; HKA: hemokinin-A; IFN: interferon; IL: interleukin; MCP: mast cell protease; NGF: nerve growth factor; NO: nitrogen oxide; NT: neurotensin; PAF: platelet activating factor; PDGF: platelet-derived growth factor; RANTES: Regulated upon Activation, Normal T Cell Expressed and Presumably Secreted; SCF: stem cell factor; SP: Substance P; SRS-A: slow releasing substance of anaphylaxis; TGF: transforming growth factor; TNF: tumor necrosis factor; TSLP: thymic stromal lymphopoietin; VEGF: vascular endothelial growth factor; VIP: vasoactive intestinal peptide; VLA: very late antigen.

Historically, physicians have struggled to differentiate between complex, multisystem illnesses and psychiatric disorders, particularly when symptoms involve cognition and mood [70]. Before biological mechanisms are established, there is an initial tendency to attribute complex and unfamiliar conditions like TILT and MCAS to stress and/or psychogenic causes. Unaware of MCAS, some physicians may mistakenly diagnose psychosomatic disorders or even Munchausen syndrome (or, in children, Munchausen syndrome by proxy) in these patients, with adverse consequences for the patients' mental health and further delaying accurate diagnosis and effective treatment.

Both MCAS and TILT have prominent neurological features. For example, organophosphate pesticides, which bind irreversibly to cholinergic receptors in the parasympathetic nervous system, appear to be among the most severe and permanently damaging TILT initiators. Correspondingly, organophosphates have been shown to trigger degranulation in human and animal mast cells [71]. The parasympathetic nervous system also modulates MC activity via a cholinergic pathway [72]. MCs play pivotal roles in regulating cerebral blood flow [73], directly affecting brain function. Notably, both MCAS and TILT patients commonly report cognitive difficulties which may be the result of reduced cerebral blood flow due to chemical exposures, such as vehicle exhaust or pesticides [74]. Brain MCs lie close to cerebral blood vessels, nerves, and the meninges, and inhabit the area postrema, choroid plexus, thalamus, hypothalamus, and limbic system, thus affecting memory, mood, and concentration. MCs can migrate between nerve tissue and lymphatics, and appear to contribute to neuroinflammation in many disorders [75-77]. For more information regarding mast cells, see Afrin et al. [78] Molderings et al. [79]; and Moon et al. [80].

Notably, during stress, corticotropin-releasing factor is secreted by the hypothalamus and, together with neurotensin, triggers MCs to release inflammatory and neurotoxic mediators, thereby disrupting the bloodbrain barrier and resulting in neuroinflammation [81]. Referring to ADHD, Song et al. [63] cite increasing evidence that MCs are involved in brain inflammation and neuropsychiatric disorders. Selective release of 
inflammatory mediators by MCs, interacting with glial cells and neurons, may activate the hypothalamic-pituitary-adrenal axis and disrupt blood-brain barrier integrity.

This physiology fits the two stages of TILT-initiation and triggering, that is, initiation by a single intense exposure, or repeated lower level exposures (pesticides, implants, drugs, etc.), which immunologically sensitize mast cells in the brain and/or other key sites. Thereafter, both chemically related and chemically unrelated, xenobiotic exposures may readily trigger mediator release by these now "twitchy" mast cells. Anticipated cognitive and mood effects might include: sudden rage (e.g., "road rage"); impulsive, violent, or abusive behaviors; addictive tendencies; mental confusion/fatigue; and/or a sense of depersonalization. MC "twitchiness" renders these cells vulnerable to a host of unrelated exposures that never bothered the person before and do not bother most people. Therefore, it is plausible that MC sensitization and triggering could explain the two stages of TILT.

By the time either MCAS or TILT is suspected, most patients have accumulated numerous diagnoses, each of which may explain a portion of their problems, but none of which account for the full range and duration of their illness. At present, most MCAS cases are classified as "idiopathic" rather than primary (i.e., of proven clonal or autoimmune origin) or secondary (i.e., due to some other inflammatory or neoplastic condition). Published preliminary findings suggest that most "idiopathic" cases likely are clonal and involve varying mutations in at least the transmembrane tyrosine kinase receptor KIT, the dominant mast cell regulatory element, and likely other $\mathrm{MC}$ regulatory elements. The widely variable MC mutations and epigenetic changes result in diverse $\mathrm{MC}$ mediator expression profiles, which in turn drive diverse clinical presentations [82].

If, in fact, TILT and MCAS are closely related conditions, they should share the same underlying pathophysiology and patients should manifest similar symptoms and intolerances. As a first step in testing this hypothesis, we used the QEESI to explore similarities and differences between TILT and MCAS.

\section{Methods}

The MCAS group consisted of patients of authors LBA and TTD seen between September 2017 and July 2019 who completed the QEESI along with their intake forms [83]. Patients were assigned a clinical score reflecting their likelihood of having MCAS $[36,83]$.

QEESI scores from MCAS patients were compared to QEESI scores derived from earlier published data involving five different groups: $\mathrm{Cl}$ individuals who identified an initiating exposure event; $\mathrm{Cl}$ individuals who reported no initiating exposure; implant recipients; Gulf War Veterans; and a control group [84]. Those with QEESI scores of 40 or greater on both the Symptom Severity and Chemical Intolerance Scales were classified as having $\mathrm{Cl}$ in our predictive model. Mean scores were compared statistically using ANOVA across the six groups using Tukey post hoc tests. 
Clinical scores for the MCAS patient group were used to predict $\mathrm{Cl}$ status using a logistic regression model. Analyses were performed using SAS software [85]. This study was approved by the University of Texas Health Science Center San Antonio Internal Review Board (approval number HSC20150821H).

\section{Results}

Percentage Meeting $\mathrm{Cl}$ Criteria by Group: There were 147 patients from the MCAS clinic, ranging in age from 16 to 75 years (mean $=40.7, S D=13.9$ ). The exposure and control comparison groups were derived from published data by Miller and Prihoda [84]. The number, percent female, age, and percentages meeting $\mathrm{Cl}$ criteria are presented in Table 3 for all six groups. Fifty-nine percent (59\%) of the MCAS clinical group fit QEESI criteria for $\mathrm{Cl}$, a somewhat higher percentage than among the Gulf War Veterans (49\%). Percentages of the other comparison groups meeting $\mathrm{Cl}$ criteria exceeded $75 \%$, except for controls (7\%).

Table 3

Percentages meeting TILT/Cl criteria by group

\begin{tabular}{|lllll|}
\hline Group & $\mathbf{n}$ & \% Female & $\begin{array}{l}\text { Age } \\
\text { Mean ( } \pm \text { se) }\end{array}$ & \% meeting criteria for TILT/CI \\
\hline Cl-exposure event $^{\text {a }}$ & 96 & $49 \%$ & $49(11)$ & $89 \%$ \\
\hline Cl-no event $^{\text {a }}$ & 90 & $82 \%$ & $51(12)$ & $81 \%$ \\
\hline Implant $^{\text {a }}$ & 87 & $50 \%$ & $50(9)$ & $75 \%$ \\
\hline MCAS group $^{\text {b }}$ & 147 & $89 \%$ & $41(14)$ & $59 \%$ \\
\hline Gulf Veterans $^{\text {a }}$ & 72 & $11 \%$ & $40(10)$ & $49 \%$ \\
\hline Controls $^{\text {a }}$ & 76 & $68 \%$ & $43(9)$ & $7 \%$ \\
\hline
\end{tabular}

a From Miller and Prihoda (1999)

b MCAS Clinical Group (Sept 2017 - July 2018)

${ }^{\mathrm{c}}$ Scores above 40 on both the QEESI Chemical Intolerance and Symptom Scales qualify as

\section{TILT/CI}

QEESI Total Scale Scores: Fig. 3 shows the distribution of total QEESI scores and masking indices by participants in these groups. In every case, controls' scores were significantly lower than for the other groups $(\mathrm{p}<.001)$. With few exceptions, the $\mathrm{Cl}$ groups scored significantly higher than other groups, whether or not they reported an intiating exposure. Regarding the Chemical Intolerance Scale, scores for the MCAS group were not significantly different from the Gulf War Veterans' scores, but were significantly 
lower than scores of all other groups. On the Other Intolerance Scale, the MCAS group scored significantly higher than the Gulf War Veterans' group $(p<.01)$; however, the MCAS group's score was statistically equivalent to the other groups' scores. On the Life Impact Scale, the MCAS group's score did not differ significantly from the Implant group's, and both were significantly higher than the Gulf War Veterans group $(\mathrm{p}<.01)$. For the Symptom Severity Scale, the Implant group and $\mathrm{Cl}$ with known exposure group scored significantly higher than the other groups $(p<.01)$. Scores for the $\mathrm{Cl}$ group without reported exposure and the MCAS groups did not differ significantly from each other. The Masking Index (a measure of ongoing exposures) was significantly greater among controls compared to the other groups $(p<.01)$, except for the Gulf War Veterans group, whose Masking Index score was not significantly different from that of controls. The MCAS group and the $\mathrm{Cl}$ group with known exposures had similarly low masking scores.

Predicted Probability of $\mathrm{Cl}$ with Increases in MCAS Scores: Logistic regression appears in Table 4. Compared to the lowest quartile (Q1), those in the 2nd quartile of MCAS scores were 2.6 times more likely to have $\mathrm{Cl}(\mathrm{p}=.027)$; those in the 3rd quartile of MCAS scores were 6.0 times more likely to have $\mathrm{Cl}(\mathrm{p}$ $=.0001)$; those in the 4 th quartile of MCAS scores were 6.2 times more likely to have $\mathrm{Cl}(p=.0001)$. Figure 4 shows that the probability of $\mathrm{Cl}$ increases as MCAS scores increase. There is an exponential increase in the probability of $\mathrm{Cl}$ with increasing MCAS scores, reaching nearly perfect prediction toward the extreme set of MCAS scores.

Table 4

Logistic Regression Model Predicting TILT Status from MCAS Quartile Scores

\begin{tabular}{|c|c|c|c|}
\hline $\begin{array}{l}\text { Quartile } \\
\text { Comparison }\end{array}$ & $\begin{array}{l}\text { Parameter Estimate } \\
\text { ( } \pm \text { se) }\end{array}$ & $\mathrm{p}$ value & $\begin{array}{l}\text { Odds Ratios } \\
\text { (95\% Confidence Limits) }\end{array}$ \\
\hline \multicolumn{4}{|c|}{ Unadjusted Maximum Likelihood Estimates } \\
\hline Q2 v Q1 & $0.96(0.44)$ & 0.0265 & $2.62(1.12-6.16)$ \\
\hline Q3 v Q1 & $1.79(0.60)$ & 0.0001 & $6.00(2.43-14.80)$ \\
\hline Q4 v Q1 & $1.83(0.47)$ & 0.0001 & $6.22(2.45-15.79)$ \\
\hline \multicolumn{4}{|c|}{$\begin{array}{l}\text { Maximum Likelihood Estimates Adjusted } \\
\text { for Age and Gender }\end{array}$} \\
\hline Q2 v Q1 & $0.96(0.44)$ & 0.0300 & $2.60(1.09-6.19)$ \\
\hline Q3 v Q1 & $1.69(0.47)$ & 0.0003 & $5.45(2.18-13.62)$ \\
\hline Q4 v Q1 & $1.79(0.48)$ & 0.0002 & $5.98(2.33-15.33)$ \\
\hline
\end{tabular}

Distribution of QEESI Scores: Figs. 5-9 show QEESI scale items (see by TILT, MCAS, and Control groups. Here we merged four groups: the three exposure groups (chemically-intolerant individuals who reported an intiating exposure, Gulf War Veterans, Implant patients) and the chemically-intolerant individuals who 
did not report an initiating exposure into one group (TILT group) for purposes of comparison against controls and MCAS patients.

\section{Symptom Severity Scale (Fig. 5)}

There were no significant differences between the TILT and MCAS groups for 8 of the 10 symptom items. For the Neuromuscular and Affective items, the TILT group's scores were slightly higher than those of the MCAS group $(p<.04)$. Both the TILT and MCAS groups reported significantly more severe symptoms than did controls $(p<.0001)$.

\section{Chemical Intolerance Scale (Fig. 6)}

TILT and MCAS groups both had significantly higher chemical intolerance scores than did controls ( $p$ $<$.0001). The TILT group's chemical intolerance scores were significantly higher than the MCAS group's scores for all items $(p<.01)$.

\section{Other Intolerance Scale (Fig. 7)}

There were no significant differences between the TILT and MCAS groups for 8 of the 10 intolerance items. Only the chlorinated tap water item was scored significantly higher by the TILT group $(p<.01)$. Only the Foods/Food Additives item was scored significantly higher by the MCAS group $(p<.03)$. Both TILT and MCAS groups scored significantly higher than controls $(p<.0001)$.

\section{Life Impact Scale (Fig. 8)}

Both TILT and MCAS groups scored significantly higher than controls $(p<.0001)$ on all Life Impact items. The TILT group consistently scored higher on 9 out of the 10 items on this scale than did the MCAS group $(p<.01)$, with the exception of the diet item where the MCAS group reported the a slightly greater impact of their illness on diet.

\section{Masking Index (Fig. 9)}

Both TILT and MCAS groups had significantly lower masking scores than did controls $(p<.0001)$, meaning that they had fewer ongoing exposures to tobacco smoke, fragrances, or caffeine which tend to hide ("mask") the relationship between symptoms and exposures. However, the MCAS group reported greater use of drugs/medications and gas stoves than did the TILT group $(p<.05)$.

\section{Discussion}

For decades, both MCAS and $\mathrm{Cl}$ patients have been misunderstood, marginalized, and often referred for mental health evaluation $[6,34,86]$. Symptoms in these patients arising from MC-neuronal interactions often are viewed as neuropsychiatric in origin, with mental health practitioners assigning diagnostic labels such as somatic symptom disorder or conversion disorder. Many psychiatric diagnoses are not 
etiologic and thus fail to define the potential role of environmental exposures/xenobiotics in initiating and perpetuating illness [78].

Some have alleged that these conditions could not be real because they involve too many symptoms in too many organ systems, with no known etiology or unifying mechanism [6, 34]. Others have invoked olfactory-limbic sensitization [87] and neurogenic inflammation [60] as potential unifying mechanisms. The result has been a stalemate in diagnosis, research, and treatment. Our results imply that environmental agents could initiate or escalate TILT/Cl, resulting in chronic, aberrant MC mediator release in potentially every tissue of the body. MCAS and TILT both involve sensitization, i.e., response amplification over time, initiated and triggered by a host of chemicals, foods, and drugs. Mast cell activation and mediator release may be driven via the "classic" IgE-mediated route to MC activation, or potentially via the panoply of non-IgE-mediated MC activation mechanisms now known to exist. We propose $\mathrm{MC}$ activation and mediator release as a plausible biological mechanism for chemical intolerance or TILT and suggest how treatment may be informed by successful therapies for MCAS.

Similarities between MCAS and TILT: In Figs. 5-8 we see that all comparison groups had statistically higher scores than did controls on the QEESI scales. We also see that the MCAS and TILT groups share strikingly similar patterns of symptoms and intolerances to structurally diverse chemicals, foods, and drugs.

\section{Symptom Severity Scale}

For eight of the 10 symptom items there was no significant difference between the MCAS and TILT groups. There was only a slight increase in severity in Affective and Neuromuscular symptoms in the TILT group compared to the MCAS group. Mediators released by mast cells in the central nervous system may explain the depression, irritability, and loss of motivation patients in both groups commonly report.

\section{Chemical Intolerance Scale}

The same classes of chemicals appear to trigger symptoms in the MCAS group as in the TILT group. However, for every chemical item, the TILT group reported significantly more severe symptoms than did the MCAS group. Notably, it appears (Fig. 6) that the most problematic triggers for many MCAS patients are fragrances, which also pose major problems for $\mathrm{Cl}$ individuals [88]. Fragrances are often used in poorly ventilated places such as restrooms or airplanes, triggering significant symptoms in growing numbers of "TILTed" and other susceptible individuals. Finding fragrance-free workplaces, schools, housing, churches, etc., can be a near-impossible quest. Fragrances have deleterious effects on cognition, mood, and breathing, and must become a principal focus for environmental and public health agencies that deal with air pollutants. Prior to the discovery of IgE, who would have guessed that just a few molecules of latex, penicillin, or peanuts could trigger allergic reactions in sensitized individuals? Belatedly, we are learning that extraordinarily low-level exposures to synthetic chemicals, such as fragrances, may trigger mast cell mediator release in previously sensitized individuals. 


\section{Other Intolerance Scale}

It is striking for the Other Intolerance Scale, there were no significant differences between the TILT and MCAS groups for eight of the 10 items. Only the Chlorinated Tap Water item was scored significantly higher by the TILT group. Many $\mathrm{Cl}$ patients find that the smell and taste of chlorinated tap water objectionable and use filtered or bottled water.

\section{Life Impact Scale}

Notably, the TILT group consistently scored higher than the MCAS group on nine of the 10 Life Impact items. One reason for this may be that individuals with TILT/CI have greater difficulty tolerating exposures commonly encountered in social activities, which can be attributed to, for example, fragrances that people wear, fragrance-emitting devices, cleaning products, candles, traffic exhaust, and various indoor and outdoor air contaminants. Even outdoor events like concerts or ballgames can entail exposures to tobacco smoke, insect repellants, BBQ smoke, mold, and chlorinated pools/spas. With such restrictions, it is understandable that depression, irritability, and loss of motivation may develop over time. Many become frustrated by healthcare providers who do not understand chemical intolerance. Costly therapies often yield little or no improvement and potentially worsen their condition. $\mathrm{Cl}$ patients, their families, friends, employers, and colleagues grow weary. Notably, both the MCAS and TILT groups and their doctors frequently recognize adverse food reactions, and patients in both groups identify specific food intolerances.

\section{Masking Index}

"Masking" results from overlapping responses to chemical inhalants, foods, and drugs, as well as an individual's tendency to addict or habituate to these substances. Masking obscures the relationship between symptoms and triggers, literally hiding the cause-and-effect relationship between them from both patients and clinicians [89].

The control group endorsed more Masking items than did the TILT and MCAS groups, consistent with our prior studies $[84,90]$. People without $\mathrm{Cl}$ or MCAS may be more apt to use alcohol, tobacco, and caffeine for their stimulatory effects. Our controls reported less difficulty with chemicals in the environment, perhaps because they were more masked and/or they were more biologically tolerant. The MCAS group reported greater use of drugs/medications which could reflect the fact that MCAS is more commonly treated with medications to prevent $\mathrm{MC}$ degranulation and/or to block $\mathrm{MC}$ mediator effects. Individuals with $\mathrm{Cl}$ often experience so many adverse drug reactions that they avoid most prescription and over-thecounter drugs, favoring alternative therapies such as herbs, homeopathy, or acupuncture [91].

Current TILT/CI Treatment: Trigger identification and avoidance, rather than medications, are mainstays for treating the symptoms of $\mathrm{Cl}$. Likewise, these are the first steps for managing MCAS. There are two principal ways to protect a patient from problem exposures: either remove the exposure from the patient 
or remove the patient from the exposure [6]. Various prophylactic medications/supplements (e.g. cromolyn) or desensitization procedures may benefit some patients.

Identifying and Assessing TILT: A systematic two-step evaluation works well for identifying patients with $\mathrm{Cl}$. First, administer the three-item Brief Environmental Exposure Sensitivity Instrument (BREESI) screener to help identify individuals who are apt to have significant intolerances for chemicals, foods, and drugs (see Palmer et al., for the BREESI three-item questionnaire) [92]. Second, if one or more BREESI items are endorsed, administer the full 50-item QEESI (http://tiltresearch.org/wpcontent/uploads/sites/30/2017/05/qeesi.pdf) (see Supplemental Material Section). These will help identify potential initiators and triggers of $\mathrm{Cl}$. A detailed exposure/symptom history and timeline coupled with the QEESI may help identify individuals whose home, work, school, or community environment should be assessed. If symptoms began or flared at a particular point in time, patients can document the severity of their symptoms by completing the QEESI Symptom Severity Scale twice to illustrate how severe their symptoms are currently as opposed to how severe they were before they became ill. This may also help clinicians discern which environmental exposure(s) may have initiated the illness and may be perpetuating symptoms. Removing initiating exposures appears to be essential for sustained improvement among TILT patients. When administered over time, the QEESI helps gauge the effectiveness of treatment and/or avoidance strategies [54, 93]. For both MCAS and TILT, a QEESI Symptom Star can be graphed based upon serial administrations of the QEESI across time. The Symptom Star facilitates communication between physician and patient by displaying symptom severity before and after the identified exposure event $[54,93,94]$ (See Fig. 10). Likewise, administering the QEESI can help researchers and clinicians gauge the success of their interventions, whether medications, avoidance, or other.

Environmental Interventions: The most effective method for identifying potential problem exposures is for an indoor air quality professional who understands $\mathrm{Cl}$ to conduct an environmental audit/investigation. An experienced evaluator can assess air flows, migration of air contaminants from an attic, basement, or attached garage; identify sources of water/humidity that foster mold or bacterial growth; and locate exposure sources, including use and storage of pesticides, fragrances, cleaning, personal care, and laundry products; and document the presence of vehicle exhaust, petroleum, glues, solvents, and tobacco smoke.

Interestingly, the MCAS group reported greater use of gas stoves than did the TILT group ( $58 \%$ vs $25 \%$ respectively), perhaps suggesting an important source and intervention for MCAS patients who use gas stoves. Historically, as early as the 1960 s, removing gas appliances has been a principal recommendation for $\mathrm{Cl}$ individuals [95].

\section{Dietary Interventions}

Both TILT and MCAS patients report adverse reactions to foods. Because food intolerances are common among these patients, but often hard to identify, their diets deserve special attention. We recommend assistance from dieticians who understand food intolerances, food addiction, and elimination diets. The 
majority of these adverse food reactions are food intolerances as opposed to classical, IgE-mediated food allergies (e.g., to peanuts) that are discoverable through skin or blood testing. In contrast, food intolerances often are "hidden" or "masked." The gold standard for identifying food intolerances involves "unmasking," that is, the rigorous elimination of suspect foods for 4 to 7 days, followed by judicious reintroduction of single foods, one-at-a-time, under close medical and dietary supervision. For a detailed description of masking, unmasking, and food intolerances, see references [96-100].

Foods themselves may be triggers, but food additives and chemical residues on foods are also potential triggers. For example, some patients exclusively eat organic food to avoid pesticide residues. There are growing concerns over a related chemical, glyphosate, introduced in 1974, now globally the most widely used herbicide since the development of genetically engineered, herbicide-tolerant crops. Contact allergies with glyphosate have been documented, and recently, glyphosate has been shown to be associated with allergic reactions in both human and animal studies [101-103].

\section{Medical Interventions}

Notably, in medical history, striking recoveries or responses to particular medications have led doctors to infer particular mechanisms. Such may be the case for TILT if the knowledge gleaned from treating MCAS patients is applied to those suffering from Cl or TILT. Up to now, there has been no demonstrable biological mechanism for CI/TILT, making it difficult to develop evidence-based treatments.

After trigger identification and avoidance strategies are implemented, potential medical interventions for $\mathrm{Cl}$ may include many of those used to treat MCAS. Many authors report success with pharmacological prophylaxis for MCAS, including the agents that prevent MC degranulation and/or reduce tissue inflammation caused by MC mediators. [50, 104, 105]. For example, impressive clinical responses to $\mathrm{H} 1 / \mathrm{H} 2$ blockers and mast cell stabilizers like cromolyn or quercetin have been observed in MCAS patients $[31,34,79-81,104]$. Similarly, cromolyn might benefit CI/TILT patients. Cromolyn, however, is poorly absorbed from mucosal surfaces and therefore must be applied fairly frequently to specific surfaces (e.g., the gastrointestinal tract, nasal mucosa, and respiratory tract) to maximize its benefit. Patients may not tolerate usual commercial preparations of cromolyn or $\mathrm{H} 1 / \mathrm{H} 2$ blockers and may require compounded formulations with no excipients or coloring.

Polyphenols or flavonoids such as quercetin and luteolin, which have "potent antioxidant, antiallergic, anti-inflammatory, and cytoprotective properties," are under investigation for MCAS treatment [104-106]. Theoharides et al. [81] report that luteolin may lessen the tissue inflammation underlying "brain fog."

Interestingly, low-dose benzodiazepines help some MCAS patients. This may be due to the presence of benzodiazapine receptors on not only neurons but also MCs [107-108], suggesting a pharmaceutical therapy targeting both the nervous and immune systems.

Various kinds of pain in various sites affect at least three-quarters of MCAS patients, and experienced physicians recommend that potential causes be evaluated and treated specifically $[79,34,13]$. Wirz and 
Molderings [50] reviewed analgesic drug options for MC-mediated acute and chronic pain.

Pharmacotherapy for TILT/Cl is by no means a simple process and still requires minimizing chemicals, foods, and medications known to precipitate adverse reactions. Furthermore, drug excipients, diluents, and food additives, including dyes and preservatives, are known to provoke symptoms in both MCAS and TILT patients and must be suspected whenever a new medication or food formulation has been introduced into the patient's regimen shortly before symptoms appear or escalate. The vast majority of medications contain so-called 'inactive ingredients' that are not listed on the label but can trigger symptoms in sensitized MCAS patients or people with TILT/CI [109]. These excipients can include "inert" fillers, binders, dyes, and preservatives in oral medications. Other possibilities include adhesives used for patch medications and plasticizers that leach from intravenous bags and tubing. Similarly, silver nanoparticles applied to plastics to prevent infection can trigger MC activation in some patients [110].

\section{Other Implications for Clinical Practice}

Mast cell degranulation and mediator release suggest an elegant explanation for TILT's numerous "unexplained" symptoms and for a host of so-called "idiopathic" illnesses sharing features of TILT. These include Gulf War Syndrome, Breast Implant Illness, some mold-related illnesses, and various other exposure-induced conditions (Figs. 1 and 2). Likewise, researchers and clinicians who wish to understand TILT-related, or overlapping conditions including fibromyalgia, chronic fatigue syndrome, depression, irritable bowel syndrome, asthma, eczema, attention deficit/hyperactivity disorder, or autism spectrum disorders $[111,112]$ need to take exposure histories that include asking when illness began or was exacerbated, whether an initiating event occurred, and whether other people (or animals) were exposed or affected.

We have observed that some of the most severely "TILTed" individuals were "initiated" by exposure to organophosphates (OPs) [90]. Groups exposed to OPs and at risk for TILT include agricultural workers, sheep dippers, occupants exposed to pesticides, Gulf War soldiers, and airline crew members exposed to "fume events" during which engine lubricants (OPs) bleed into cabin air [6, 113]. OPs irreversibly bind acetylcholinesterase. The enzyme paraoxonase, or PON1, helps determine a person's ability to detoxify organophosphates [114] and may explain why certain individuals are particularly susceptible to both TILT and to MCAS.

\section{Implications for Regulatory Agencies/Authorities}

Any policymakers or regulatory bodies dealing with chemicals, foods, and/or drugs need to understand TILT and mast cell sensitization.

\section{Directions for Future Research}

With this new understanding of the role of mast cells in TILT, important questions arise concerning individual susceptibility differences that may be due to prior exposures, genetics, epigenetics, and 
nutrition. Mast cell activation and mediator release suggest a rational and parsimonious explanation for both the initiation and triggering phases of TILT.

Given the overlap between the TILT and MCAS populations, and the fact that mast cell mediators could explain much about TILT, future research should examine the following questions: (1) What proportion of the TILT population harbors detectable MC activation as determined by a rigorous diagnostic MCAS workup? (2) Do patients with TILT have somatic MC regulatory gene mutations as already found in most MCAS patients? (3) If so, are there recurrent mutations reflecting differing clonality patterns (e.g., in KIT) [26] characterizing differing subsets of TILT patients, perhaps even "fingerprinting" particular initiating exposures, and (4) Would specific treatments targeting MCs or their mediators prove helpful for the TILT population as a whole or for certain subsets?

\section{Conclusion}

Mast cell activation and mediator release appear to explain decades of observations by physicians and their patients who report multi-system symptoms and intolerances following a wide variety of exposures. We have demonstrated that as the likelihood of patients' having CI/TILT increases, their likelihood of having MCAS similarly increases, to a near-perfect correspondence at the high ends of these scales. An association is, of course, not proof of causation. Nevertheless, the strikingly similar symptom and intolerance patterns for the MCAS and TILT patients suggest a shared biological mechanism which we posit to be mast cell sensitization by xenobiotics and subsequent degranulation with re-exposure.

Traditional referral pathways send TILT/CI patients and their healthcare providers on a "wild goose chase," diverting them from addressing the environmental (TILT) and biological (mast cell) origins of patients' conditions. Faced with patients suffering from complex conditions affecting multiple organ systems with symptoms that wax and wane unpredictably, clinicians should ask themselves two questions: 1) Could MCs be causing these problems? 2) Could environmental exposures be driving MC activation and mediator release?

Understanding the connection between TILT and mast cells has the potential to reveal hidden links between environmental exposures and illness, and improve practice in medicine, psychology, public health, environmental health, and regulatory toxicology.

\section{Declarations}

Authors' contributions: CSM conceived and designed this work. LBA and TTD provided insight and guidance regarding mast cells, and were responsible for the acquisition of the clinical data. RFP acquired the archived data, and analyzed and interpreted the statistical results. NAA provided content related to chemical intolerance and regulatory concerns in Europe and the U.S. All authors contributed substantially to the drafting and revisions of the manuscript and approved the submitted version. All authors are 
responsible for the accuracy and integrity of the manuscript and data. The authors do not claim any conflict of interest.

ACKNOWLEDGEMENT: This research was made possible by the generous support of the Marilyn Brachman Hoffman Foundation.

Ethical Approval and Consent to participate. This study was approved by the University of Texas Health Science Center San Antonio Internal Review Board (approval number HSC20150821H).

Consent for publication: Not applicable.

Availability of supporting data: The datasets during and/or analyzed during the current study available from the corresponding author on reasonable request.

Competing interests. The authors declare that they have no competing interests.

Funding: This work was funded by a grant from the Marilyn Brachman Hoffman Foundation, Dallas, Texas (TX).

Authors' contributions: CSM conceived and designed this work. LA and TD provided insight and guidance regarding mast cells, and were responsible for the acquisition of the clinical data. RFP acquired the archived data, and analyzed and interpreted the statistical results. All authors contributed substantially to the drafting and revisions of the manuscript and approved the submitted version. All authors are responsible for the accuracy and integrity of the manuscript and data.

Acknowledgements: The authors thank Dr. Carlos Jaén, Chairman of the Department of Family and Community Medicine, University of Texas Health Science Center at San Antonio, for his visionary support and encouragement. This research was made possible by generous funding from the Marilyn Brachman Hoffman Foundation.

Authors' information: All authors have approved the manuscript before submission and have agreed to the order of authorship. We verify that all data and figures are compliant with the transparency and reproducibility standards of both the field and journal.

\section{References}

1. Steinemann A. 2018. National Prevalence and Effects of Multiple Chemical Sensitivities. Journal of Occupational and Environmental Medicine 60(3):e152-e156

2. Hojo S, Mizukoshi A, Azuma K, Okumura J, Ishikawa S, Miyata M, Mizuki M, Ogura H, Sakabe K. 2018. Survey on changes in subjective symptoms, onset/trigger factors, allergic diseases, and chemical exposures in the past decade of Japanese patients with multiple chemical sensitivity. International Journal of Hygiene and Environmental Health. 221(8):1085-1096. 
3. Macy E. 2018. Chapter 16 - Multiple Drug Intolerance Syndrome, Editor(s): David A. Khan, Aleena Banerji, Drug Allergy Testing, Elsevier. 165-168, ISBN 9780323485517, https://doi.org/10.1016/B9780-323-48551-7.00016-X.

4. Young E, Stoneham MD, Petruckevitch A, Barton J, Rona R. 1994. A population study of food intolerance, The Lancet.343(8906):1127-1130, https://doi.org/10.1016/S0140-6736(94)90234-8.

5. Rona RJ, Keil T, Summers C, Gislason D, Zuidmeer L, Sodergren E, Sigurdardottir ST, Lindner T, Goldhahn K, Dahlstrom J, McBride D, Madsen C. 2007. The prevalence of food allergy: A metaanalysis. Journal of Allergy and Clinical Immunology. 120 (3): 638-646, https://doi.org/10.1016/j.jaci.2007.05.026.

6. Ashford N, Miller C. 1998. Chemical Exposures: Low Levels and High Stakes. New York: Von Nostrand Reingold.

7. Masri S, Miller CS, Palmer RF, Ashford N. Toxicant-induced loss of tolerance for chemicals, foods, and drugs: assessing patterns of exposure behind a global phenomenon Article DOI: 10.1186/s12302-021-00504-z (in Press)

8. Miller CS. Toxicant-induced loss of tolerance. Addiction. 2001 Jan;96(1):115-37. doi: 10.1046/j.13600443.2001.9611159.x. PMID: 11177524.

9. Rossi S, Pitidis A. Multiple Chemical Sensitivity: Review of the State of the Art in Epidemiology, Diagnosis, and Future Perspectives. J Occup Environ Med. 2018;60(2):138-146. doi:10.1097/JOM.0000000000001215

10. Dantoft TM, Andersson L, Nordin S, Skovbjerg S. Chemical intolerance. Curr Rheumatol Rev. 2015;11(2):167-84. doi: 10.2174/157339711102150702111101. PMID: 26088215.

11. Clauw DJ. Potential mechanisms in chemical intolerance and related conditions. Ann NY Acad Sci. 2001 Mar;933:235-53. doi: 10.1111/j.1749-6632.2001.tb05828.x. PMID: 12000024.

12. Crivellato E, Ribatti D. 2010. The mast cell: an evolutionary perspective. Biol Rev Camb Philos Soc. 85(2):347-60. doi: 10.1111/j.1469-185X.2009.00105.x.

13. Afrin LB. Mast cell activation disease and the modern epidemic of chronic inflammatory disease. Transl Res. 2016;174:33-59. doi:10.1016/j.trsl. 2016.01.003

14. Krystel-Whittemore M, Dileepan KN, Wood JG. 2016. Mast Cell: A Multi-Functional Master Cell. Frontiers in immunology. 6(620). doi:10.3389/fimmu.2015.00620

15. Vinuya RZ, Simon MR, Schwartz LB. Elevated serum tryptase levels in a patient with protracted anaphylaxis. Ann Allergy. 1994;73(3):232-234.

16. Janiszewski, J J. Bienenstock, and M. G. Blennerhassett Picomolar doses of substance P trigger electrical responses in mast cells without degranulation. 1994, 267 (1): C138-C145

17. Afrin LB, Ackerley MB, Bluestein LS, et al. Diagnosis of mast cell activation syndrome: a global "consensus-2". Diagnosis (Berl). 2020;8(2):137-152. Published 2020 Apr 22. doi:10.1515/dx-20200005 
18. Theoharides TC, Tsilioni I, Ren H. 2019. Recent advances in our understanding of mast cell activation - or should it be mast cell mediator disorders? Expert Rev Clin Immunol. 15(6):639-656. doi:10.1080/1744666X.2019.1596800.

19. Wong GW, Zhuo L, Kimata K, Lam BK, Satoh N, Stevens RL. Ancient origin of mast cells. Biochem Biophys Res Commun. 2014;451(2):314-318. doi:10.1016/j.bbrc.2014.07.124

20. Theoharides TC et al. Differential release of mast cell mediators and the pathogenesis of inflammation. Immunological Reviews 2007;217(1):65-78.

21. Ibelgaufts H. "Mast Cells" entry in "Cytokines On-line Pathfinder Encyclopedia," 2021, https://www.cells-talk.com, last accessed May 17, 2021.

22. Lippert U, Artuc M, Grützkau A, et al. Human skin mast cells express $\mathrm{H} 2$ and $\mathrm{H} 4$, but not $\mathrm{H} 3$ receptors. J Invest Dermatol. 2004;123(1):116-123. doi:10.1111/j.0022-202X.2004.22721.x

23. He SH, Xie H, Fu YL. Inhibition of tryptase release from human colon mast cells by histamine receptor antagonists. Asian Pac J Allergy Immunol. 2005;23(1):35-39.

24. Lippert U, Möller A, Welker P, Artuc M, Henz BM. Inhibition of cytokine secretion from human leukemic mast cells and basophils by $\mathrm{H} 1$ - and $\mathrm{H} 2$-receptor antagonists [published correction appears in Exp Dermatol. 2002 Aug;11(4):386.]. Exp Dermatol. 2000;9(2):118-124. doi:10.1034/j.16000625.2000.009002118.x

25. Petersen LJ, Hansen U, Kristensen JK, Nielsen H, Skov PS, Nielsen HJ. Studies on mast cells and histamine release in psoriasis: the effect of ranitidine. Acta Derm Venereol. 1998;78(3):190-193. doi:10.1080/000155598441503

26. Molderings GJ, Meis K, Kolck UW, Homann J, Frieling T. 2010. Comparative analysis of mutation of tyrosine kinase kit in mast cells from patients with systemic mast cell activation syndrome and healthy subjects. Immunogenetics. 62(11-12):721-7. doi: 10.1007/s00251-010-0474-8.

27. Wilson BS, Pfeiffer JR, Oliver JM. Observing Fceri Signaling from the Inside of the Mast Cell Membrane. J Cell Biol 29 May 2000; 149 (5): 1131-1142. doi:

https://doi.org/10.1083/jcb.149.5.1131

28. Masao Yamaguchi, Chris S. Lantz, Hans C. Oettgen, Ildy M. Katona, Tony Fleming, Ichiro Miyajima, Jean-Pierre Kinet, Stephen J. Galli; IgE Enhances Mouse Mast Cell FceRI Expression In Vitro and In Vivo: Evidence for a Novel Amplification Mechanism in IgE-dependent Reactions. J Exp Med 17 February 1997; 185 (4): 663-672. doi: https://doi.org/10.1084/jem.185.4.663

29. Abraham SN, and St John AL. 2010. Mast cell-orchestrated immunity to pathogens. Nature reviews. Immunology, 10(6), 440-452. doi:10.1038/nri2782

30. Monticelli S and Leoni C. 2017. Epigenetic and transcriptional control of mast cell responses. F1000Research, 6, 2064. doi:10.12688/f1000research.12384.1

31. Weiler CR, Austen KF, Akin C, Barkoff MS, Bernstein JA, Bonadonna P, Butterfield JH, Carter M, Fox CC, Maitland A, Pongdee T, Mustafa SS, Ravi A, Vliagoftis H, Schwartz LB. 2019. Mast cell activation syndrome (MCAS) diagnosis and management. Journal of Allergy and Clinical Immunology, 144 (4): $883-896$ 
32. Valent P, Akin C, Arock M, Brockow K, Butterfield J, Carter MC, Castells M, Escribano L, Hartmann K, Lieberman P, Nedoszytko B, Orfao A, Schwartz LB, Sotlar K, Sperr WR, Triggiani M, Valenta R, Horny HP, Metcalfe 2012. Definitions, Criteria and Global Classification of Mast Cell Disorders with Special Reference to Mast Cell Activation Syndromes: A Consensus Proposal. Int Arch Allergy Immunol. 157:215-225 DOI: 10.1159/000328760

33. Valent P and Akin C. 2019. Doctor, I Think I Am Suffering from MCAS: Differential Diagnosis and Separating Facts from Fiction. The Journal of Allergy and Clinical Immunology: In Practice. 7(4):1109-1114. https://doi.org/10.1016/j.jaip.2018.11.045

34. Afrin LB, Self S, Menk J, and Lazarchick J. 2017. Characterization of Mast Cell Activation Syndrome. The American journal of the medical sciences, 353(3), 207-215. doi:10.1016/j.amjms.2016.12.013

35. Zenker N, and Afrin LB. 2015. Utilities of Various Mast Cell Mediators in Diagnosing Mast Cell Activation Syndrome. Blood, 126(23): 5174. Accessed 11/15/19. Retrieved from http://www.bloodjournal.org/content/126/23/5174.

36. Molderings GJ, Brettner S, Homann J, \& Afrin LB. 2011. Mast cell activation disease: a concise practical guide for diagnostic workup and therapeutic options. Journal of hematology \& oncology, 4, 10. doi:10.1186/1756-8722-4-10

37. Afrin LB, Dempsey TT, Rosenthal LS, Dorff2019.Successful mast-cell-targeted treatment of chronic dyspareunia, vaginitis, and dysfunctional uterine bleeding, Journal of Obstetrics and Gynaecology, 39:5, 664-669, DOI: 10.1080/01443615.2018.1550475

38. Tuuminen T, Rinne KS. Severe Sequelae to Mold-Related Illness as Demonstrated in Two Finnish Cohorts. Front Immunol. 2017;8:382. Published 2017 Apr 3. doi:10.3389/fimmu.2017.00382

39. Hojo, S, Kumano H, Yoshino H, Kakuta K, \& Ishikawa S. 2003. Application of Quick Environment Exposure Sensitivity Inventory $\left(\mathrm{QEESI}{ }^{\circledR}\right)$ for Japanese population: study of reliability and validity of the questionnaire. Toxicol Ind Health. 19(2-6):41-49.

40. Dupas D and Dagorne MA. 2013 Multiple chemical sensitivity: a diagnosis not to be missed. 30(2):99-104.

41. Jeon BH, Lee SH, \& Kim HA. 2012. A validation of the Korean version of QEESI@ (The Quick Environmental Exposure and Sensitivity Inventory). Korean J Occup Environ Med. 24(1):96-114.

42. Nordin S and Andersson L. 2010. Evaluation of a Swedish version of the quick environmental exposure and sensitivity inventory. Int. Arch. Occup. Envi. 83(1):95-104.

43. Skovbjerg S, Berg ND, Elberling J \& Christensen KB. 2012. Evaluation of the quick environmental exposure and sensitivity inventory in a Danish population. J Environ Public Health. doi: $10.1155 / 2012 / 304314$.

44. Miller CS. 2001. The compelling anomaly of chemical intolerance. Ann N Y Acad Sci. 933:1-23.

45. Miller CS. 1997. Toxicant-induced loss of tolerance-an emerging theory of disease? Environ Health Perspect. 105 Suppl 2:445-453. 
46. Genuis, SJ. 2010. Sensitivity-related illness: The escalating pandemic of allergy, food intolerance and chemical sensitivity. Science of the Total Environment: 408 (24): 6047-6061.

47. Lessof M. 1997. Meetings report: Report of multiple chemical sensitivities (MCS) workshop, Berlin, Germany, 21-23 February 1996. PCS/96.29 IPCS, Geneva, Switzerland. Human Exp Toxicol.16:233-4.

48. 1996. Conclusions and recommendations of a workshop on multiple chemical sensitivities (MCS). Reg Toxicol Pharmacol. 24:S188-9.

49. 1999. Idiopathic environmental intolerances, Journal of Allergy and Clinical Immunology. 103(1):3640.

50. Wirz S and Molderings J. 2017. Practical Guide for Treatment of Pain in Patients with Systemic Mast Cell Activation. Disease Pain Physician. 20:E849-E861

51. Caress SM, Steinemann AC. 2004. Prevalence of multiple chemical sensitivities: a population-based study in the southeastern United States. Am J Public Health. 94(5): 746-747.

52. Azuma K, Uchiyama I, Katoh T, Ogata H, Arashidani K, Kunugita N. 2015. Prevalence and Characteristics of Chemical Intolerance: A Japanese Population-Based Study. Arch Environ Occup Health; 70:341-353.

53. Kreutzer R, Neutra RR, Lashuay N. 1999. Prevalence of people reporting sensitivities to chemicals in a population-based survey. Am J Epidemiol. 150(1): 1-12.

54. Hojo S, Sakabe K, Ishikawa S, Miyata M, Kumano H. 2009. Evaluation of subjective symptoms of Japanese patients with multiple chemical sensitivity using QEESIC Environmental Health and Preventive Medicine (14): 267-275.

55. Miller CS. Are we on the threshold of a new theory of disease? Toxicant-induced loss of tolerance and its relationship to addiction and abdiction. Toxicology and Environmental Health. Volume: 15 issue: 3-4, page(s): 284-294, 1999. New ref here for QEESI scoreing

56. Roberts LJ. 1988. Carcinoid syndrome and disorders of systemic mast-cell activation including systemic mastocytosis. Endocrinol Metab Clin North Am. 17(2):415-36.

57. Roberts LJ. 1984. Recurrent syncope due to systemic mastocytosis. Hypertension. 6(2, Pt 1):285-94.

58. Li N, Zhang X, Dong H, Hu Y, Qian Y. 2017. Bidirectional relationship of mast cells-neurovascular unit communication in neuroinflammation and its involvement in POCD. Brain Res. 322:60-69.

59. Rossi S, Pitidis A. Multiple Chemical Sensitivity: Review of the State of the Art in Epidemiology, Diagnosis, and Future Perspectives. Journal of Occupational and Environmental Medicine: February 2018 - Volume 60 - Issue 2 - p 138-146 doi: 10.1097/JOM.0000000000001215

60. Meggs WJ. Neurogenic switching: a hypothesis for a mechanism for shifting the site of inflammation in allergy and chemical sensitivity. Health Perspect., 103 (1995), pp. 54-56

61. Dantoft TM, Elberling J, Brix S, Szecsi PB, Vesterhauge S, Skovbjerg S. An elevated pro-inflammatory cytokine profile in multiple chemical sensitivity. Psychoneuroendocrinology2014; 40:140-150.

62. Silverman AJ, Sutherland AK, Wilhelm M, Silver R. 2000. Mast Cells Migrate from Blood to Brain Journal of Neuroscience. 20 (1) 401-408; DOI: https://doi.org/10.1523/JNEUROSCI.20-01- 
00401.2000

63. Song Y, Lu M, Yuan H, Chen T and Han X: Mast cell-mediated neuroinflammation may have a role in attention deficit hyperactivity disorder. Exp Ther Med 20: 714-726, 2020

64. Theoharides TC. Neuroendocrinology of mast cells: Challenges and controversies. Exp Dermatol. 2017 Sep;26(9):751-759. doi: 10.1111/exd.13288. Epub 2017

65. Theoharides TC. The impact of psychological stress on mast cells. Ann Allergy Asthma Immunol. 2020 Jul 17:S1081-1206(20)30484-1. doi: 10.1016/j.anai.2020.07.007. Epub ahead of print. PMID: 32687989.

66. Petra Al, Panagiotidou S, Hatziagelaki E, Stewart JM, Conti P, Theoharides TC. Gut-Microbiota-Brain Axis and Its Effect on Neuropsychiatric Disorders With Suspected Immune Dysregulation. Clin Ther. 2015 May 1;37(5):984-95. doi: 10.1016/j.clinthera.2015.04.002.

67. De Luca C, Scordo MG, Cesareo E, Pastore S, Mariani S, Maiani G, Stancato A, Loreti B, Valacchi G, Lubrano C, Raskovic D, De Padova L, Genovesi G, Korkina LG. Biological definition of multiple chemical sensitivity from redox state and cytokine profiling and not from polymorphisms of xenobiotic-metabolizing enzymes. Toxicol. Appl. Pharmacol., 248 (2010), pp. 285-292

68. Belpomme D, Campagnac $C$ and Irigaray $P$ : Reliable disease biomarkers characterizing and identifying electrohypersensi-tivity and multiple chemical sensitivity as two etiopathogenic aspects of a unique pathological disorder. Rev Environ Health. 30:251-271. 2015.

69. Kimata H. Effect of exposure to volatile organic compounds on plasma levels of neuropeptides, nerve growth factor and histamine in patients with self-reported multiple chemical sensitivity. Int. J. Hyg Environ. Health, 207 (2004), pp. 159-163

70. Bransfield RC and Freidman KJ. 2019. Differentiating Psychosomatic, Somatopsychic, Multisystem Illnesses and Medical Uncertainty. 7(4), 114; https://doi.org/10.3390/healthcare7040114

71. Xiong S and Rodgers K. 1997. Effects of malathion metabolites on degranulation of and mediator release by human and rat basophilic cells. J Toxicol Environ Health. 6;51(2):159-75.

72. Forsythe P. 2015. The Parasympathetic Nervous System as a Regulator of Mast Cell Function. In: Hughes M., McNagny K. (eds) Mast Cells. Methods in Molecular Biology (Methods and Protocols), vol 1220. Humana Press, New York, NY.

73. Lindsberg PJ, Strbian D, Karjalainen-Lindsberg ML. 2010. Mast cells as early responders in the regulation of acute blood-brain barrier changes after cerebral ischemia and hemorrhage. Cereb. Blood Flow Metab.30:689-702.

74. Bunegin L, Mitzel HC, Miller CS, Gelineau JF, Tolstykh GP. 2001. Cognitive performance and cerebrohemodynamics associated with the Persian Gulf Syndrome. Toxicol Ind Health. 17(4):128-37.

75. Medeiros WLG Jr., Bandeira IP, Franzoi AEA, Brandão WN, Santos Durão ACCD, Gonçalves MVM. 2019. Mast cells: A key component in the pathogenesis of Neuromyelitis Optica Spectrum Disorder? Immunobiology. pii: S0171-2985(19)30089-0.

76. Pang X, Letourneau R, Rozniecki JJ, Wang L, Theoharides TC. 1996. Definitive characterization of rat hypothalamic mast cells, Neuroscience 73(3):889-902. https://doi.org/10.1016/0306- 
4522(95)00606-0.

77. Nautiyal K. Beyond allergy: Mast cells mediate brain-behavior-immune interactions. http://grantome.com/grant/NIH/F31-MH084384-02, accessed 11/15/19

78. Afrin LB, Pöhlau D, Raithel M, Haenisch B , Dumoulin FL, Homann J ,Mauer UM, Harzer S, GJ Molderings. 2015. Mast cell activation disease: An underappreciated cause of neurologic and psychiatric symptoms and diseases. Brain, Behavior, and Immunity. 50: 314-321

79. Molderings G, Haenisch B, Brettner S, Homann J, Menzen M, Dumoulin FL, Panse J, Butterfield J, Afrin LB. 2016. Pharmacological treatment options for mast cell activation disease. NaunynSchmiedeberg's Arch Pharmacol. 389:671-694.

80. Moon TC, Befus AD, \& Kulka M. 2014. Mast cell mediators: their differential release and the secretory pathways involved. Frontiers in immunology, 5, 569. doi:10.3389/fimmu.2014.00569

81. Theoharides TC, Stewart JM, Hatziagelaki E, Kolaitis G. 2015. Brain "fog," inflammation and obesity: key aspects of neuropsychiatric disorders improved by luteolin. Frontiers in neuroscience. 9 (225). doi:10.3389/fnins.2015.00225

82. Molderings GJ. 2015. The genetic basis of mast cell activation disease - looking through a glass darkly. Crit Rev Oncol Hematol. 93: pp. 75-89

83. Afrin LB and Molderings GJ. 2014. A concise, practical guide to diagnostic assessment for mast cell activation disease World J Hematol. 3(1): 1-17

84. Miller CS and Prihoda T. 1999. The Environmental Exposure and Sensitivity Inventory (EESI): a standardized approach for measuring chemical intolerances for research and clinical applications. Toxicology and Industrial Health.15: 370-385.

85. SAS Institute Inc. 2014. SAS® 9.4 Statements: Reference, Third Edition. Cary, NC: SAS Institute Inc.

86. Bornschein S, Hausteiner C, Zilker T, Forst H. 2002. Psychiatric and somatic disorders and multiple chemical sensitivity (MCS) in 264 'environmental patients'. Psychological Medicine, 32(8), 13871394. doi:10.1017/S0033291702006554.

87. Bell, R., Miller, C. S. and Schwartz, G. E.1992. An olfactory-limbic model of multiple chemical sensitivity syndrome: possible relationship to kindling and affective spectrum disorders. Biol Psychiatry, 32: 218-42.

88. Steinemann A. 2019. International Prevalence of Chemical Sensitivity, Co-Prevalence with Asthma and Autism, and Effects from Fragranced Consumer Products. Air Quality, Atmosphere and Health. 12(5): 519-527. https://doi.org/10.1007/s11869-019-00672-1

89. Miller, C. S. (2000). Mechanisms of action of addictive stimuli. Addiction, 96, 115-139.

90. Miller CS, and Mitzel HC, 1997. Chemical Sensitivity Attributed to Pesticide Exposure Versus Remodeling. Archives of Environmental Health. 50(2):119-129.

91. Gibson PR, Nicole-Marie AE, Ruding LA Perceived treatment efficacy for conventional and alternative therapies reported by persons with multiple chemical sensitivity. 2003 Environmental Health Perspectives 111:12 CID: https://doi.org/10.1289/ehp.5936 
92. Palmer RF, Jaén CR, Perales RB, Rincon R, Forster JN, Miller CS. Three questions for identifying chemically intolerant individuals in clinical and epidemiological populations: The Brief Environmental Exposure and Sensitivity Inventory (BREESI). 2020; Sept 16. PloS One, https://doi.org/10.1371/journal.pone.0238296.

93. Yun MJ, Kang DM, Lee K-H, Kim YK, Kim JE. 2013. Multiple chemical sensitivity caused by exposure to ignition coal fumes: a case report. Annals of Occupational and Environmental Medicine. 25:32.

94. Imai N and Imai Y. Necessity of counseling institutions for sick building syndrome patients. In Sabah A. Abdul-Wahab Eds, Sick Building Syndrome: in Public Buildings and Workplaces, p365. Springer Science \& Business Media, 2011 - Technology \& Engineering - 591 pages

95. Randolph TG. 1962. Human Ecology and Susceptibility to the Chemical Environment. Springfield, Illinois: Charles C. Thomas.

96. Randolph TG. The Descriptive Features of Food Addiction. Addictive Eating and Drinking. Quarterly Journal of Studies on Alcohol 1956 17:2, 198-224

97. Randolph TG. Dynamics, Diagnosis, and Treatment of Food Allergy. Otolaryngologic Clinics of North America. Volume 7, Issue 3, October 1974, Pages 617-635

98. Bell IR, Schwartz GE, Peterson JM, Amend D, Stini WA. (1993) Possible Time-dependent Sensitization to Xenobiotics: Self-reported Illness from Chemical Odors, Foods, and Opiate Drugs in an Older Adult Population, Archives of Environmental Health: An International Journal, 48:5, 315-327, DOI: 10.1080/00039896.1993.9936720

99. Miller, C. S. (2000). Mechanisms of action of addictive stimuli. Addiction, 96, 115-139.

100. Brostoff J. and Gamlin L. The complete guide to food allergy and intolerance. 1998 pp.380 pp. Bloomsbury Publishing Ltd. London. ISBN :0747534306

101. Rodriguez A, Echechipia S, O'Laguibel JM, et al. 1997. Occupational contact allergy to herbicide glyphosate (abstract). J Allergy Clin Immunol. 99: S336

102. Hoppin JA, Umbach DM, Long S, London SJ, Henneberger PK. 2016. Pesticides are associated with allergic and non-allergic wheeze among male farmers Environ. Health Perspect., 125 (4): p. 535

103. Tang Q, Tang J, Ren X, Li C. 2020. Glyphosate exposure induces inflammatory responses in the small intestine and alters gut microbial composition in rats. Environmental Pollution. 261:114129

104. Shaik Y, Caraffa A, Ronconi G, Lessiani G, Conti P. 2018. Impact of polyphenols on mast cells with special emphasis on the effect of quercetin and luteolin. Central-European journal of immunology, 43(4):476-481. doi:10.5114/ceji.2018.81347

105. Oksaharju A, Kankainen M, Kekkonen RA, Lindstedt KA, Kovanen PT, Korpela R, Miettinen M. 2011. Probiotic Lactobacillus rhamnosus downregulates FCER1 and HRH4 expression in human mast cells. World J Gastroenterol. 17(6):750-9. doi: 10.3748/wjg.v17.i6.750.

106. Theoharides TC. Luteolin supplements: All that glitters is not gold [published online ahead of print, 2020 Nov 7]. Biofactors. 2020;10.1002/biof.1689. doi:10.1002/biof.1689 
107. Taniguchi T, Wang JK, Spector S. 1980. Properties of $(3 \mathrm{H})$ diazepam binding to rat peritoneal mast cells. Life Sci. 14;27(2):171-8. DOI: 10.1016/0024-3205(80)90460-9

108. Haenisch B, Huber M, Wilhelm T, Steffens M, Molderings GJ. 2013. Investigation into mechanisms mediating the inhibitory effect of 1,4-benzodiazepines on mast cells by gene expression profiling. Life Sci. 92(6-7):345-51. doi: 10.1016/j.lfs.2013.01.010.

109. Schofield JR and Afrin LB. 2019. Recognition and Management of Medication Excipient Reactivity in Patients with Mast Cell Activation Syndrome. The American Journal of the Medical Sciences. 357(6): 507-511, https://doi.org/10.1016/j.amjms.2019.03.005.

110. Alsaleh NB, Persaud I, Brown JM. 2016. Silver Nanoparticle-Directed Mast Cell Degranulation Is Mediated through Calcium and PI3K Signaling Independent of the High Affinity IgE Receptor. PloS one, 11(12), e0167366. doi:10.1371/journal.pone.0167366

111. Heilbrun LP, Palmer RF, Jaen CR, Svoboda MD, Miller CS, Perkins J. 2015. Maternal Chemical and Drug Intolerances: Potential Risk Factors for Autism and Attention Deficit Hyperactivity Disorder (ADHD). The Journal of the American Board of Family Medicine. 28(4):461-70., DOI:10.3122/jabfm.2015.04.140192.

112. Theoharides TC. 2009. Autism spectrum disorders and mastocytosis. Int J Immunopathol Pharmacol. 22(4):859-65.

113. Winder C, Balouet JC. Aerotoxic syndrome: Adverse health effects following exposure to jet oil mist during commercial flights. In: Eddington, I, editor, Towards a Safe and Civil Society, Proceedings of International Congress on Occupational Health 2000, ICOH, Brisbane, 2000, pp 196-199

114. Jansen KL, Coleabc TB, Park SS, Furlong CE, Costa LG. 2009. Paraoxonase 1 (PON1) modulates the toxicity of mixed organophosphorus compounds. Toxicology and Applied Pharmacology. 236 (2): 142-153.

\section{Figures}




\section{Indoor Air Volatile Organic \\ Compounds (VOCs) \\ - New carpet \\ - Plasticizers \\ - Formaldehyde \\ - Fragrances \\ - Mold VOCs}

\section{Combustion-related}

Products

- Engine exhaust

- Tobacco smoke

- Oil well fire smoke

- Natural gas

- Tar/asphalt

- Burn pits

- Soldering/welding

- Building fires

\section{Solvents}

- Glues

- Paints

- Gasoline

- Nail polish/remover
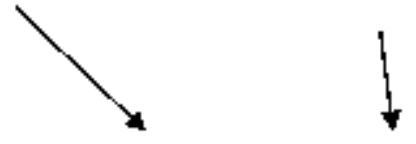

TOXICANT-INDUCED
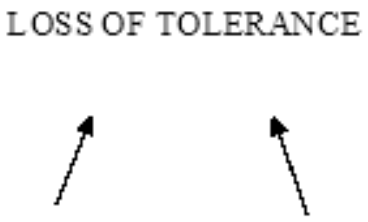

Oil and Petroleum

Products

- Oil spills

- Fracking
Drugs/Medical Devices

- Vaccines

- Anesthetics

- Implants

- Antibiotics

- Chemotherapy

Pesticides

- Organophosphates

- Carbamates

- Pyridostigmine bromide

- Pentachlorophenol

- Pyrethrins/pyrethroids

- DEET

- Airline "fume events" (tricresyl phosphate)

\section{Figure 1}

Potential Initiators and Triggers for TILT. 
Neuropsych ological

- Autism Spectrum Disorders (ASD)

- Attention Deficit/Hyperactivity Disorder (ADHD)

- Depression, Bipolar Disorder

- Anxiety

- Migraines

- Seizures

- Confusion, memory and concentration difficulties

\section{Gastrointestinal}

- Food intolerances

- Irritable Bowel Syndrome (IBS)

- Diarrhea or -...nt:..nt:-.

Connective Tissue/Musculoskeletal

- Fibromyalgia

- Arthritis

- Temporomandibular Joint Dysfunction (TMJ)

- Lupus and other autoimmune diseases

\section{Cardiovas cular}

- Arrhythmias

- Hypertension

- Hypotension

- Raynaud's Phenomenon

\section{Respiratory}

- Asthma

- Reactive Airways Dys function Syndrome (RADS)

- Toluene diisocy anate (TDI) hrmersensitivity

Ear, Nose and Throat

- Rhinitis/sinusitis

- Polyps

- Recurrent ear and other infections

- Dizziness

- Tinnitus

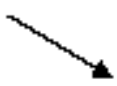

Miscellaneous Syndromes

- Chronic Fatigue Syndrome

- GulfWar Illness

- Post-9/11, oil spills, and other disasters

- Hives

- Other rashes and

- Breast Implant Illness skin eruptions

Figure 2

Conditions that may have their origins in TILT 

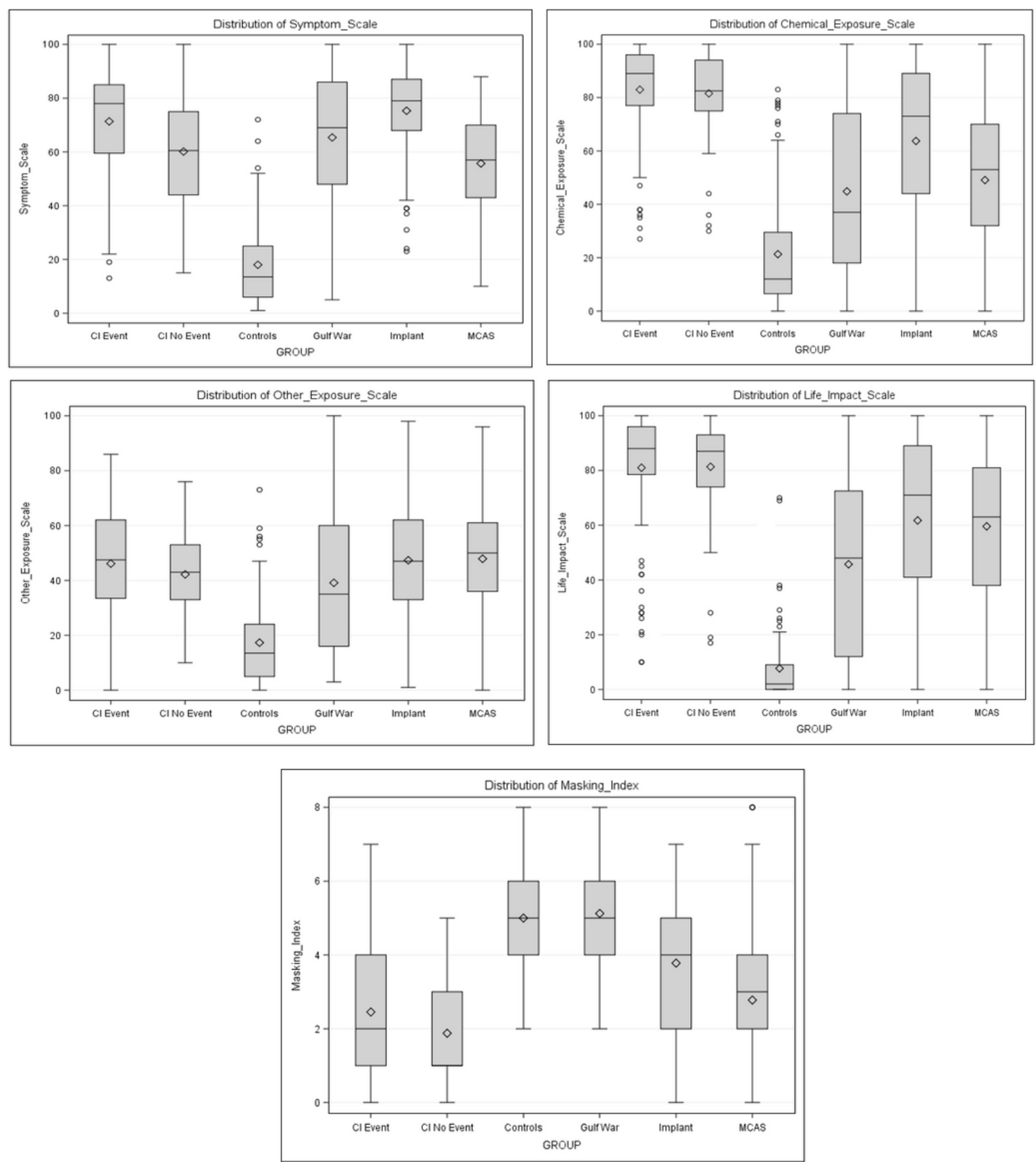

Figure 3

QEESI Total Scale Scores by Group 


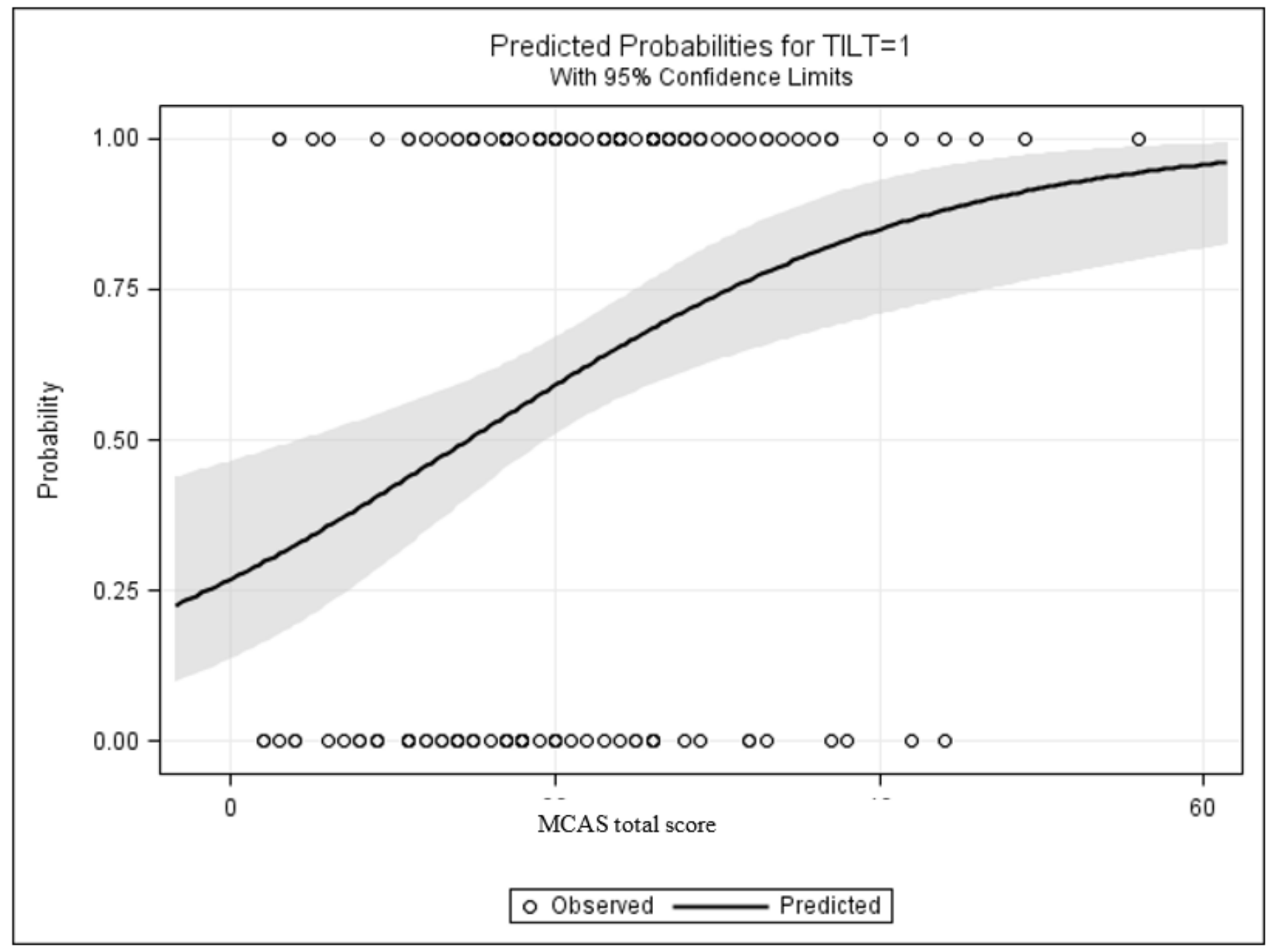

Figure 4

Predicted Probability of TILT with Increases in MCAS scores 


\section{Symptom Severity by Group \\ - Controls $\square$ MCAS DTILT}

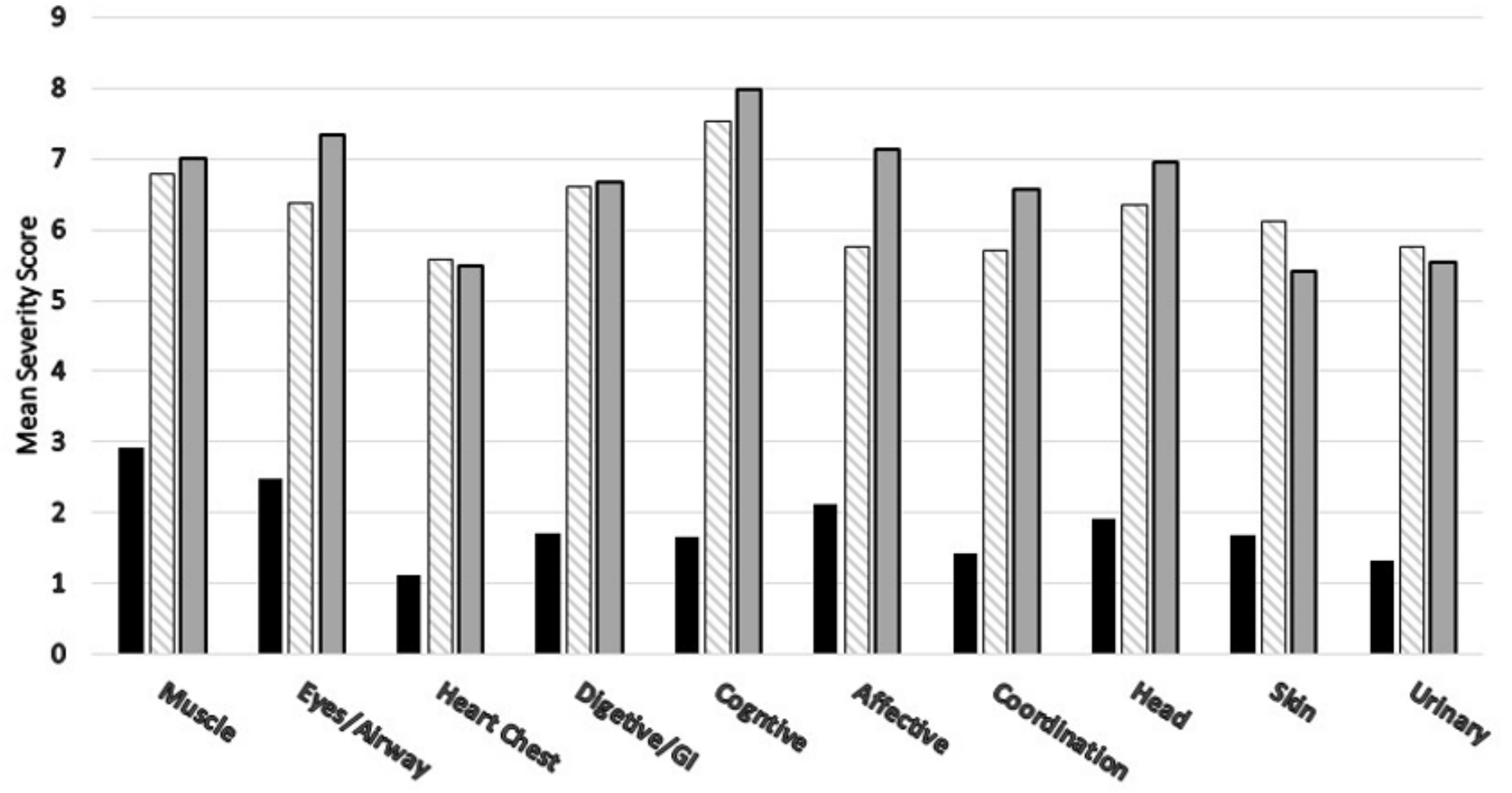

Figure 5

Distribution of QEESI Symptom Severity Scale Items for TILT, MCAS and Control Groups 
Chemical Intolerances by Group

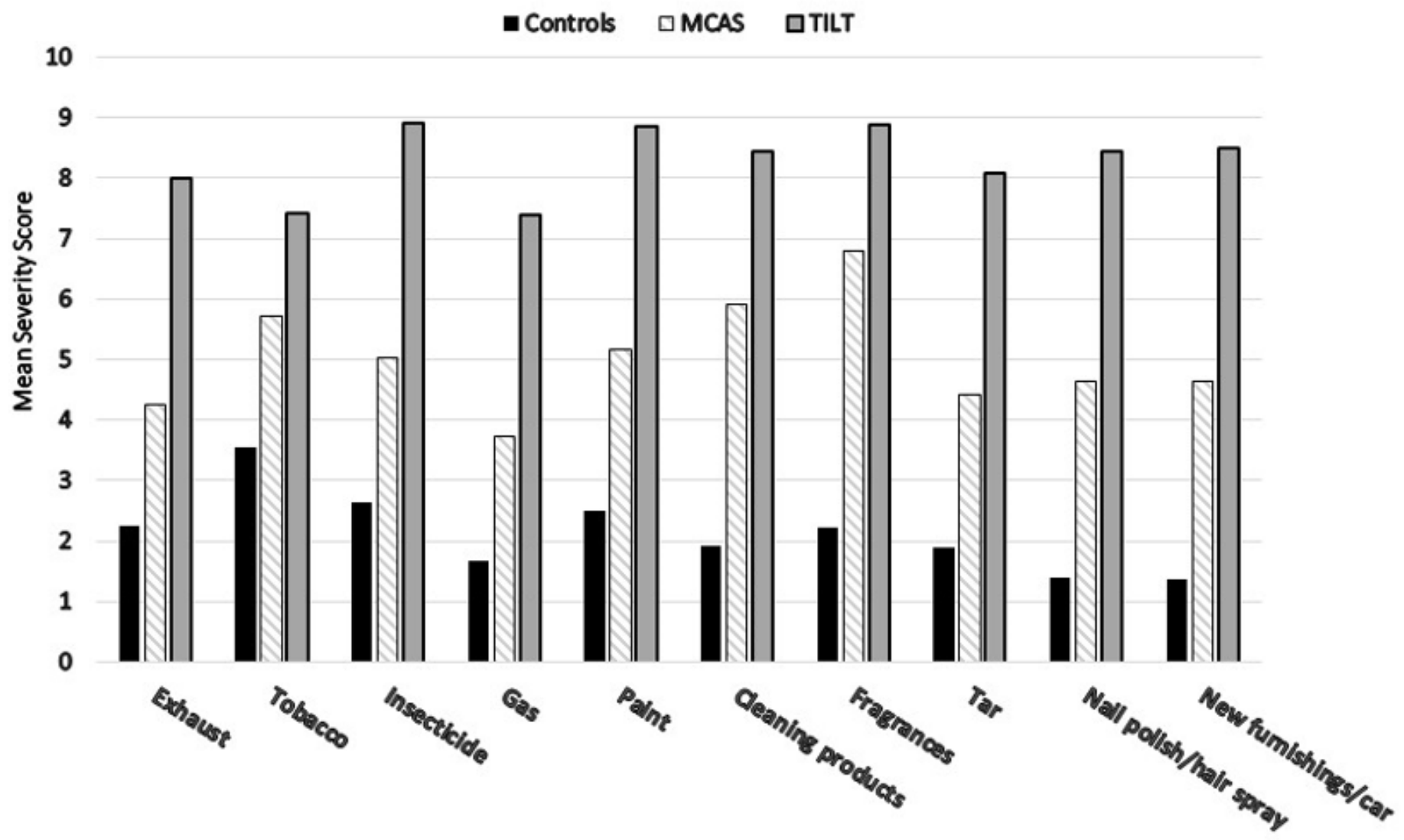

Figure 6

Distribution of QEESI Chemical Intolerance Scale Items for TILT, MCAS and Control Groups 
Other Intolerances by Group

- Controls $\square$ MCAS ITILT

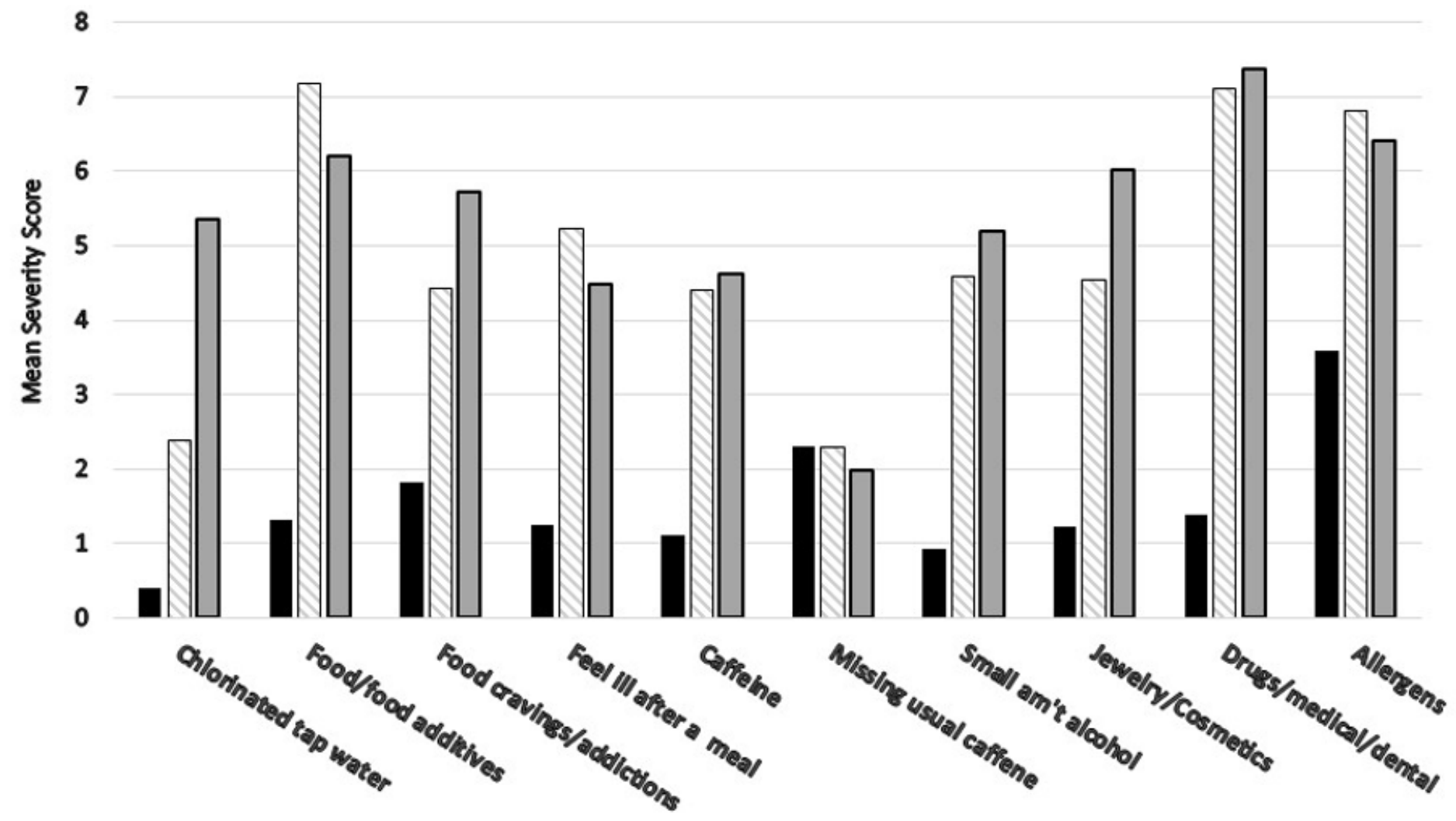

Figure 7

Distribution of QEESI Other Intolerance Scale Items for TILT, MCAS and Control groups 


\section{Life Impact by Group}

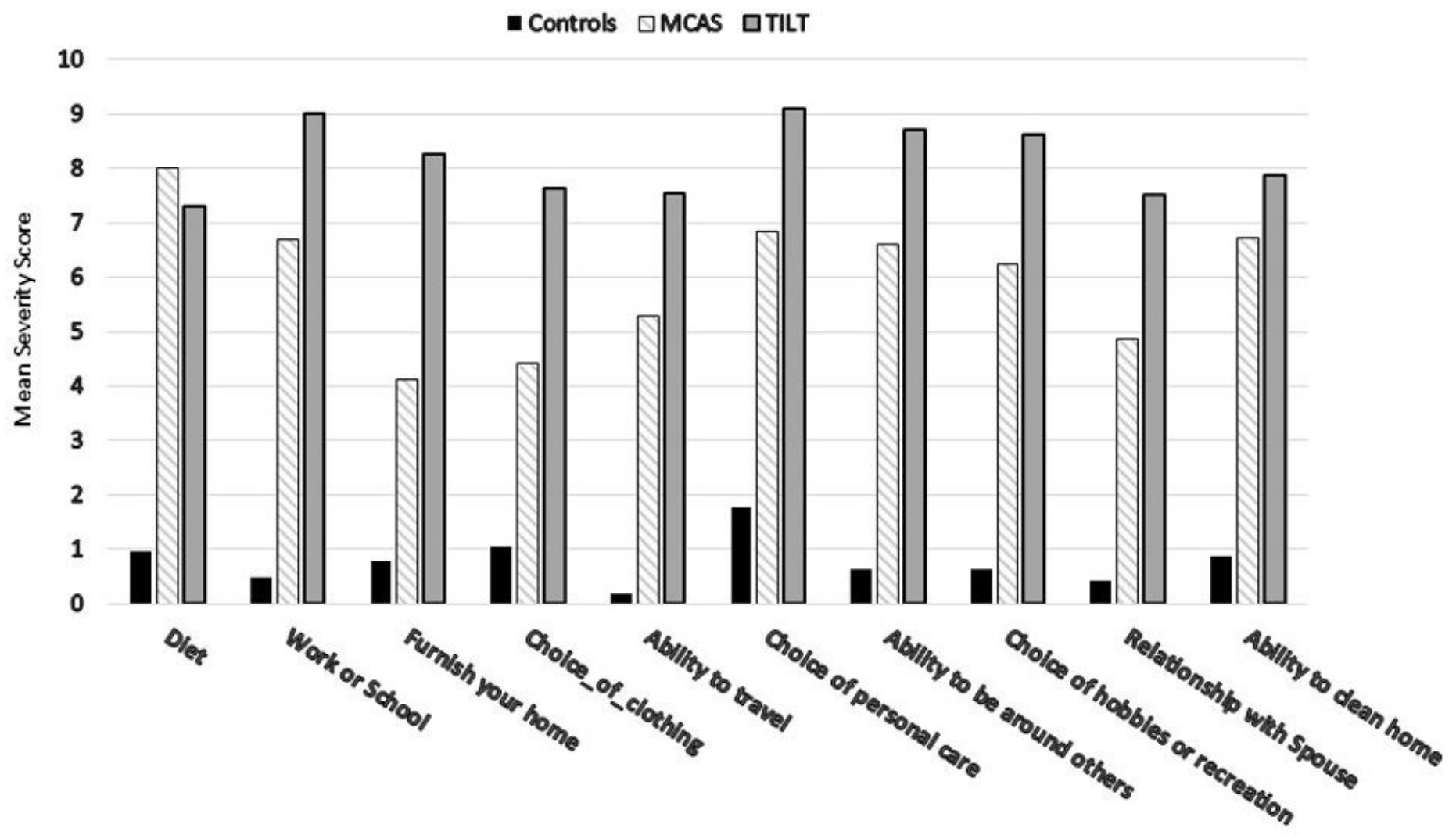

Figure 8

Distribution of QEESI Life Impact Scale Items for TILT, MCAS and Control groups 


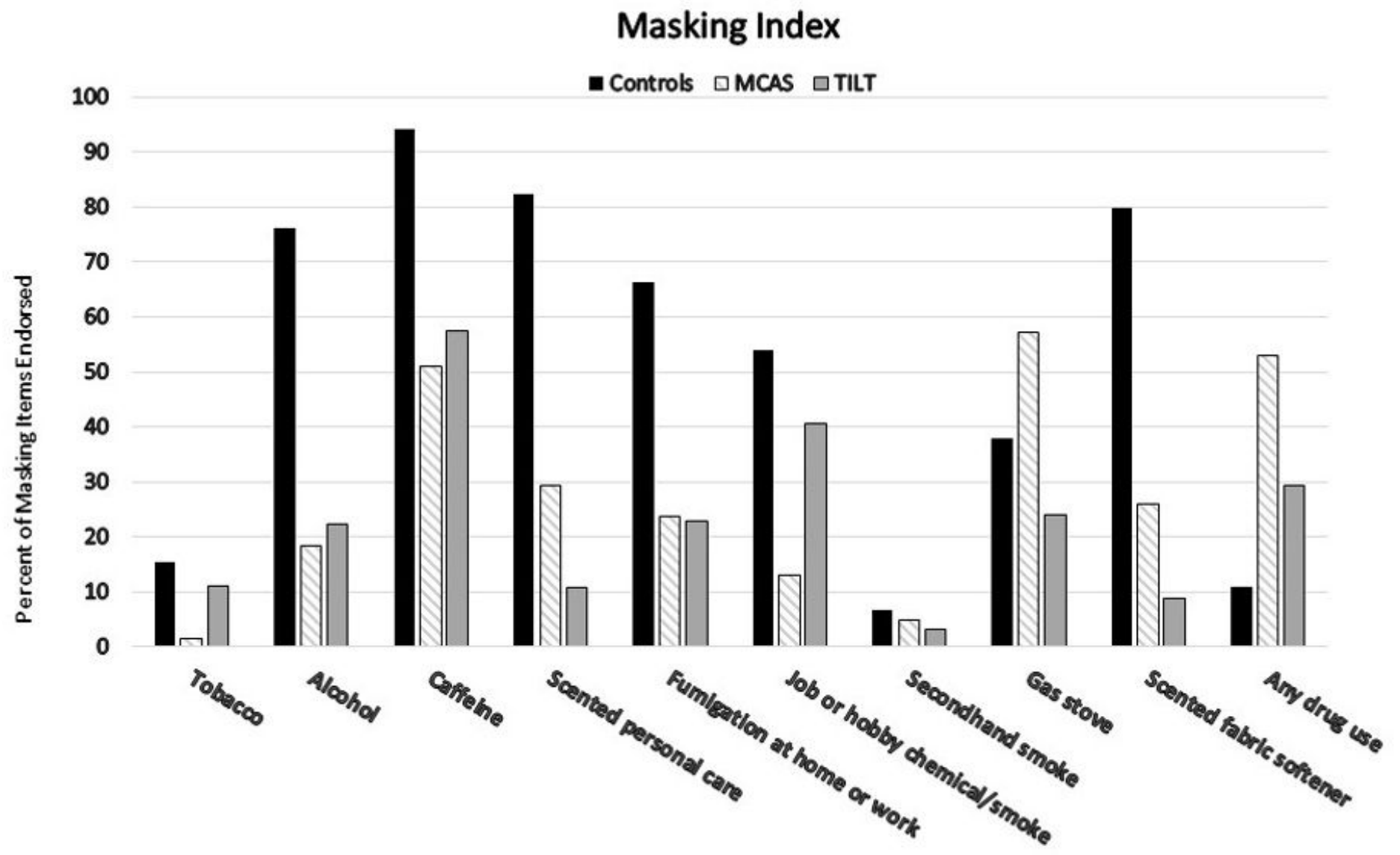

Figure 9

Distribution of QEESI Masking Index Items for TILT, MCAS and Control groups

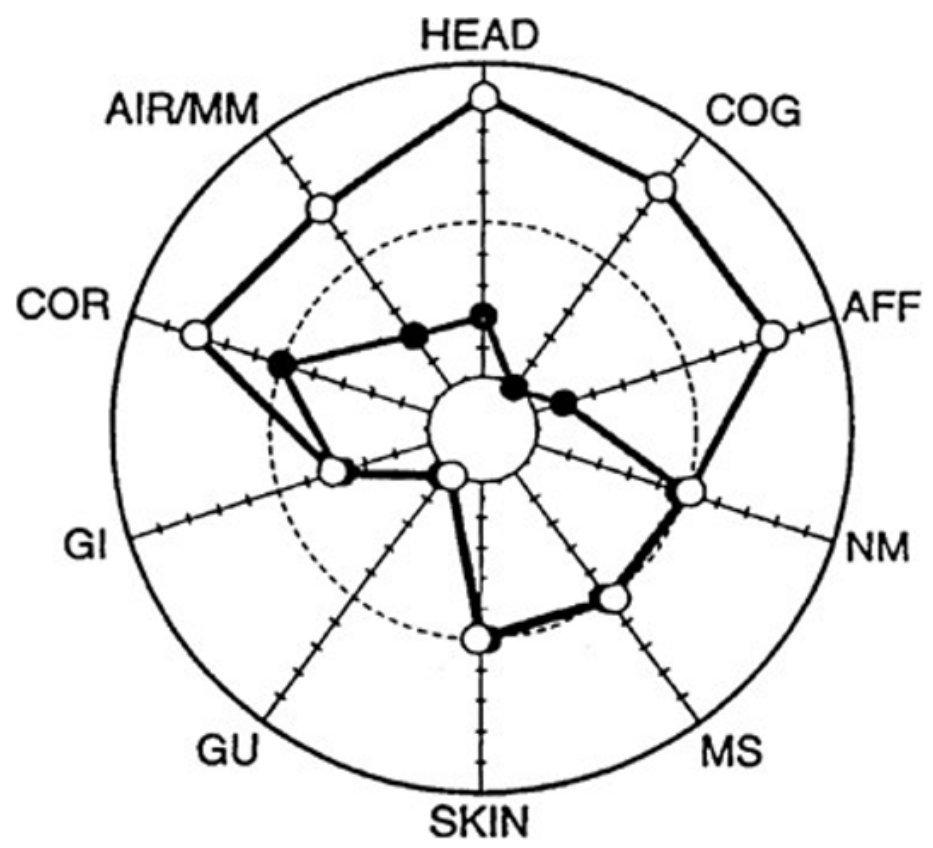

Symptom severity in an individual before $(\bullet)$ and after $(\circ)$ an exposure event (e.g., pesticide application, indoor air contaminants, chemical spills). Two good examples of how the Symptom Star has been used in patient care are demonstrated in case reports by Yun et al., (2013) [93] and Imai and Imai (2011) [94]. Terms: HEAD = head-related symptoms; $\mathrm{COG}=$ cognitive symptoms; $\mathrm{AFF}=$ affective symptoms; $\mathrm{NM}=$ neuromuscular symptoms; MS = musculoskeletal symptoms; SKIN = skin-related symptoms; GU = genitourinary symptoms; GI = gastrointestinal symptoms; $\mathrm{COR}=$ heart/chest-related symptoms; AIR/MM = airway or mucous membrane symptoms.

Figure 10 
QEESI Symptom Star. Source: Miller and Prihoda (1999)

\section{Supplementary Files}

This is a list of supplementary files associated with this preprint. Click to download.

- QuickEnvironmentalExposureSensitivityInventoryorQEESI.pdf 